\title{
Grado de conocimiento del adjetivo "intangibles", y su relación con la identificación, reconocimiento, medición, valoración y revelación de "intangibles" en la información contable de las empresas en Popayán. Un análisis descriptivo y econométrico*
}

doi:10.11144/Javeriana.cc16-40.gcai

\section{Zoraida Ramírez-Gutiérrez}

Docente, Departamento de Ciencias Contables, Universidad del Cauca, UniCauca, Popayán, Colombia. Coordinadora del Grupo de Estudio e Investigación en Finanzas y Gestión (GREIFG), Universidad del Cauca. Contadora pública, Universidad del Quindío, Armenia, Colombia. Especialista en administración financiera, Universidad Gran Colombia, Armenia, Colombia. Magíster en administración económica y financiera, Universidad Tecnológica de Pereira, UTP, Pereira, Colombia. Magíster en administración de empresas con énfasis en finanzas corporativas, Universidad Viña del Mar, UVM, Chile. Estudiante de doctorado en contabilidad y finanzas corporativas, Universidad de Valencia, UV, España.

Correo electrónico: zramirez@unicauca.edu.co

\section{Andrés Mauricio Gómez-Sánchez}

Docente, Departamento de Ciencias Económicas, Universidad del Cauca, Popayán, Colombia. Miembro del grupo de investigación Entropía, Universidad del Cauca. Economista, Universidad del Valle, UniValle, Cali, Colombia. Especialista, gerencia de proyectos, Universidad del Cauca, UniCauca, Popayán, Colombia. Magíster en economía aplicada, Universidad del Valle, UniValle, Cali, Colombia. Correo electrónico: amgomez@unicauca.edu.co

\footnotetext{
* Artículo de reflexión.
} 
Resumen Este artículo de reflexión pretende mostrar por medio de metodologías cualitativas (metodología Delphi y estudio de casos) y cuantitativas (econometría), el grado de conocimiento del término o adjetivo intangible y su asociación con la identificación, reconocimiento, medición y valoración, a efectos de la revelación de intangibles en la información contable y financiera de las organizaciones. Con la metodología Delphi se genera evidencia empírica con la ayuda de propietarios de empresas, procesadores y usuarios de información financiera, lo que mediante el estudio de casos se contrasta con las entrevistas y la información contable que ha sido revelada por empresas comerciales, industriales y de servicios de la ciudad de Popayán, Cauca. El trabajo de campo tiene como objetivo relacionar las variables grado de conocimiento del adjetivo intangible, con el grado de identificación y reconocimiento de intangibles en las empresas, para indagar sobre la importancia en la generación de valor de los mismos y, por tanto, la imperiosa necesidad de generar modelos que brinden posibilidades para la sistematización, medición y valoración de intangibles, como paso necesario e indispensable para la revelación y/o divulgación de los mismos en la información contable y financiera.

Palabras clave Intangibles; identificación y reconocimiento contable; medición y valoración contable; revelación contable; econometría; metodología Delphi; estudio de caso.

Códigos JEL A12, C01, G12, G30

\section{Amount of Knowledge of the Adjective "Intangibles" and Its Relationship with the Identification, Recognition, Measurement, Valuation, and Disclosure of "Intangibles" in the Accounting Information of Companies in Popayan. A Descriptive and Econometric Analysis}

\footnotetext{
Abstract This reflection article aims to show by means of qualitative methodologies (Delphi methodology and
}

case study) and quantitative (econometrics), the amount of knowledge it is had of the term or adjective intangible and its association with the identification, recognition, measurement, and valuation, to the effect of the disclosure of intangibles in the accounting and financial information of companies. By means of the Delphi methodology we generated empirical evidence, with the support of company owners, processors, and users of financial information, which, through case studies, is contrasted with the interviews and accounting information disclosed by commercial, industrial, and service companies in Popayan, Cauca. The objective of the field work is to relate the variables amount of knowledge of the adjective intangible with the degree of identification and recognition of intangibles in companies, with the objective of inquiring regarding the importance of their value generation, and thus, the imperative need to generate models that create possibilities for the systematization, measurement, and valuation of intangibles. This is a necessary and vital step for their disclosure in the financial and accounting information.

Keywords Intangibles; accounting identification and recognition; accounting measurement and valuation; accounting disclosure; econometrics; Delphi methodology; case study.

\section{Grau de conhecimento do adjetivo "intangíveis", e seu relacionamento com identificação, reconhecimento, mensuração, avaliação e evidenciação de "intangíveis" na informação contábil das empresas em Popayán. Análise descritiva e econométrica}

Resumo Este artigo de reflexão objetiva mostrar por meio de metodologias qualitativas (metodologia Delphi e estudo de casos) e quantitativas (econometria), o grau de conhecimento do termo ou adjetivo intangível e sua associação com identificação, reconhecimento, mensuração e avaliação, a efeitos da divulgação de intangíveis na infor- 
mação contábil e financeira das organizações. Usando a metodologia Delphi gera-se evidencia empírica com a ajuda de donos de empresas, processadores e utentes de informação financeira, o que é contrastado mediante estudo de casos com entrevistas e informação contábil que já foi apresentada por empresas comerciais, industriais e de serviços da cidade de Popayán, Cauca. O trabalho de campo objetiva relacionar as variáveis grau de conhecimento do adjetivo intangível com grau de identificação e reconhecimento de intangíveis nas empresas para investigar sobre a sua importância na geração de valor e, portanto, a imperiosa necessidade de gerar modelos que fornecem possibilidades para a sistematização, mensuração e avaliação de intangíveis, como passo necessário e indispensável para a sua evidenciação e/ou divulgação na informação contábil e financeira.

Palavras-chave Intangíveis; identificação e reconhecimento contábil; mensuração e avaliação contábil; revelação contábil; econometria; metodologia Delphi; estudo de caso.

\section{Introducción}

En el mundo entero hay una necesidad creciente de demostrar la importancia de los intangibles $^{1}$, y su relación directa con la generación o destrucción de valor en las organizaciones. Una de las categorías vinculadas a este adjetivo son los "activos intangibles", definidos como:

1 Entiéndase intangibles como algo que no vemos, que no tocamos, aquello que no tiene sustancia física, aquello que no tiene corporeidad. Es solo un adjetivo, un calificativo que se le da a algo. En ciertos casos, ese intangible puede tomar cuerpo, presencia, verse o tocarse con alguna finalidad material. Es un adjetivo que puede ser dado a diversos sustantivos, como actividades, recursos, obligaciones, ingresos, gastos. Y entre los sustantivos más utilizados: los activos.
Fuentes generadoras de valor (derechos sobre beneficios futuros) que carecen de sustancia física y son generados por medio de la innovación (descubrimiento), diseños organizativos únicos o prácticas de gestión de los recursos humanos. Con frecuencia, los intangibles están estrechamente vinculados a los activos materiales y financieros de cara a la creación de valor y el crecimiento económico (Lev, 2003, p. 21).

El problema real se centra en la capacidad de reconocer estos recursos, para poder medirlos, valorarlos e incorporarlos a la información contable y financiera. Así, se hace necesario mostrar evidencia empírica de la relevancia de los intangibles y de su grado de identificación y reconocimiento, por parte de quienes preparan y usan los informes, en empresas del sector industrial, comercial, de servicios, y aquellas del sector de la tecnología, que son propias de la era del conocimiento. A su vez, es importante recalcar la necesidad de abordar el grado de conocimiento del término o adjetivo intangible y el dominio de métodos de medición y valoración de intangibles, por parte de los procesadores de información, como variables que se complementan, para hacer posible la revelación y/o divulgación de intangibles en la información contable y financiera.

Hay evidencia teórica del crecimiento e importancia de los intangibles, como explicación de la generación de riqueza y valor en las organizaciones, a partir de la comparación de los valores de mercado y los valores en libros, y es posible que la multiplicidad de actores involucrados con las organizaciones así lo reconozca. 
El problema se centra en que no hay evidencia empírica que contribuya a un análisis de relaciones y/o variables que se entrelacen en función de la revelación contable de los intangibles, a efectos de demostrar que es un adjetivo representativo (que genera o destruye valor), y que tiene la capacidad de generar ingresos o gastos futuros.

Por ello, en este artículo de reflexión sobre la temática de los intangibles y por la necesidad de visibilizarlos en los informes contables y financieros, se presenta una metodología novedosa de procesamiento de información cualitativa, en el Análisis Delphi y el estudio de casos, que termina con información cuantitativa en un modelo econométrico, que permite que la probabilidad de revelación de intangibles en la información contable y financiera, esté en función de la relación de las variables conocimiento, identificación y reconocimiento, y medición-valoración, para los procesadores de información. Así, este artículo se divide en seis capítulos, además de la introducción; en el primero se aborda una lista de algunos modelos de valoración de intangibles, con el fin de mostrar que es una temática que aborda la gestión pero no la inmersión en los estados financieros; en el segundo apartado se demuestra con algunos ejemplos la evidencia empírica de intangibles relevantes y su relación directa con la generación de beneficios futuros; en el tercero se detalla la metodología; en el cuarto se analizan los resultados de la metodología Delphi; en el quinto se muestran resultados del estudio de caso; en el sexto apartado se propone un modelo econométrico, para concluir en el análisis de variables enla- zadas con la probabilidad de revelación de intangibles, dado el grado de conocimiento, de identificación y reconocimiento, y de métodos de medición y valoración.

\section{Muestra contrastada de algunos modelos de valoración de intangibles}

Hay características muy propias de los intangibles (Lev, 2003), que resaltan la dificultad para su reconocimiento y revelación, como la escalabilidad, que es el potencial de creación de valor, a partir de la no escasez (no rivalidad) y de los rendimientos crecientes. Esto es como se señala, porque los intangibles están inmersos en las dinámicas de la sociedad del conocimiento, muy presente en la actualidad, y que motiva el esparcimiento de estos artefactos (intangibles) por la economía y por el mercado, siendo posible darles una multiplicidad de usos (no rivalidad). Las redes depositan y facilitan el tránsito de intangibles, al hacer visible una utilidad creciente de las ideas, del conocimiento y de la investigación (rendimientos crecientes). Son esas características, muy propias de los intangibles, a diferencia de los tangibles del mundo material, las que justifican la necesidad apremiante que desde hace algunos años se viene dando al tema de la gestión de los intangibles.

La economía de los intangibles tiene su esencia en el análisis de costos y beneficios, por lo que pueden ser portadores o destructores de valor. Las características que les permiten ser generadores de beneficios y por tanto de valor son la escalabilidad (ubicuidad y rendimientos 
crecientes), y las economías de red (retroalimentación positiva, externalidades y estándares industriales). Y los principales costos asociados a los intangibles (destructores de valor) son la exclusión parcial, el elevado riesgo y la no transmisibilidad (Lev, 2003, p. 68).

Ahora bien, en este estudio, la pretensión no es quedarse exclusivamente en ese campo de la gestión y/o la economía, sino trascender a la necesidad de hacerlos visibles en los informes contables y financieros. Según Baruch Lev (2003, p. 69), para que los intangibles puedan ser considerados como activos y permitir la inclusión en los estados financieros, se deben cumplir tres premisas fundamentales:

1. Que la empresa ejerza un grado de control considerable sobre el activo (capacidad de retención de la mayoría de los beneficios generados)

2. Que el riesgo de fracaso comercial sea considerablemente bajo; $y$

3. Que existan oportunidades para conceder licencias de explotación.

Una forma de demostrar la gran importancia y necesidad de reconocimiento de los intangi- bles en la información financiera de las organizaciones, es hacer una revisión detallada de los métodos y/o modelos que han surgido desde los años 80 y 90 del siglo XX, que han tenido como motivante gestionar multiplicidad de perspectivas relativas al capital intelectual, para avanzar en propuestas de identificación y medición. Aun así, se resalta que estos modelos no alcanzan una propuesta de incorporación y revelación en la información contable, por lo que se presentan como informes paralelos o alternativos, preparados de manera flexible y en concordancia con la naturaleza de cada organización.

Por ello, se presenta como soporte preliminar, sin hacer parte fundamental de este trabajo empírico, una muestra contrastada de 17 modelos de valoración de intangibles que han ido apareciendo, por la necesidad de reconocer la existencia de los intangibles y de mostrarlos en informes paralelos a los contables y/o financieros, en los que hasta el momento no se hace fácil visibilizarlos.

A manera de contrastación, en la tabla 1 se identifican las variables diferenciadoras o ítems específicos para cada uno de los modelos, con el objetivo de precisar el campo de acción desde la descripción empírica de este trabajo. 


\begin{tabular}{|c|c|c|c|}
\hline Modelo & Línea de argumentación & $\begin{array}{c}\text { Clasificación de } \\
\text { intangibles }\end{array}$ & Indicadores \\
\hline $\begin{array}{l}\text { 1. Skandia Navigator } \\
\text { o Navegador Skandia } \\
\text { (Leif Edvinsson, 1992- } \\
\text { 1997) }\end{array}$ & $\begin{array}{l}\text { Diferencia entre los valores de mercado } \\
\text { y los valores en libros, de la empresa. } \\
\text { El valor de mercado de la empresa está } \\
\text { integrado por el capital financiero y el } \\
\text { capital intelectual. }\end{array}$ & $\begin{array}{l}\text { - Capital humano } \\
\text { - Capital estructural. } \\
\text { Dividido en clientes, } \\
\text { procesos y capacidad de } \\
\text { innovación }\end{array}$ & $\begin{array}{l}\text { Indicadores de medida } \\
\text { absoluta } \\
\text { Activos totales } \\
\text { Inversión en } \\
\text { desarrollo de nuevos } \\
\text { mercados } \\
\text { Inversión en } \\
\text { tecnologías de la } \\
\text { información, TI, para } \\
\text { ventas, servicio y } \\
\text { apoyo } \\
\text { Inversión en servicio } \\
\text { a clientes } \\
\text { Inversión en apoyo } \\
\text { y entrenamiento } \\
\text { de empleados para } \\
\text { nuevos productos. } \\
\text { Inversión en } \\
\text { identificación de } \\
\text { marca } \\
\text { Índices de eficiencia } \\
\text { Valor de mercado } \\
\text { Índice de satisfacción } \\
\text { de clientes } \\
\text { Índice de liderazgo } \\
\text { Índice de motivación } \\
\text { Retención de } \\
\text { empleados } \\
\text { Índice de horas de } \\
\text { entrenamiento }\end{array}$ \\
\hline $\begin{array}{l}\text { 2. Proceso de creación } \\
\text { del conocimiento } \\
\text { (Ikujiro Nonaka \& } \\
\text { Hirotaka Takeuchi, } \\
\text { 1995) }\end{array}$ & $\begin{array}{l}\text { Proceso de interacción entre el } \\
\text { conocimiento táctico y explícito, } \\
\text { manejando una espiral de transformación } \\
\text { ontológica interna de conocimiento. }\end{array}$ & $\begin{array}{l}\text { - Socialización } \\
\text { - Exteriorización } \\
\text { - Combinación } \\
\text { - Interiorización }\end{array}$ & $\begin{array}{l}\text { Indicadores } \\
\text { de creación de } \\
\text { conocimiento }\end{array}$ \\
\hline $\begin{array}{l}\text { 3. Intangible Assets } \\
\text { Monitor (Karl-Erik } \\
\text { Sveiby, 1996) }\end{array}$ & $\begin{array}{l}\text { Propone que las organizaciones escojan } \\
\text { una selección de indicadores en función } \\
\text { de su capacidad para cubrir el área de: } \\
\text { Crecimiento/renovación, eficiencia y } \\
\text { estabilidad. }\end{array}$ & $\begin{array}{l}\text { - Activos de estructura } \\
\text { interna } \\
\text { - Activos de estructura } \\
\text { externa } \\
\text { - Activos de competencia } \\
\text { individual }\end{array}$ & $\begin{array}{l}\text { Indicadores de } \\
\text { crecimiento/ } \\
\text { renovación } \\
\text { Indicadores de } \\
\text { eficiencia } \\
\text { Indicadores de } \\
\text { estabilidad }\end{array}$ \\
\hline
\end{tabular}




\section{ANÁLISIS DESCRIPTIVO Y ECONOMÉTRICO A ACTIVOS INTANGIBLES / Z. RAMÍREZ, A. GÓMEZ / 117}

\begin{tabular}{|c|c|c|c|}
\hline Modelo & Línea de argumentación & $\begin{array}{c}\text { Clasificación de } \\
\text { intangibles }\end{array}$ & Indicadores \\
\hline $\begin{array}{l}\text { 4. Balanced Business } \\
\text { Scorecard (Robert } \\
\text { Kaplan \& David } \\
\text { Norton, 1992, 1996) }\end{array}$ & $\begin{array}{l}\text { Contribuye a transformar el objetivo y } \\
\text { la estrategia de la unidad de negocio en } \\
\text { objetivos e indicadores tangibles. }\end{array}$ & $\begin{array}{l}\text { - Perspectiva financiera } \\
\text { - Perspectiva del cliente } \\
\text { - Perspectiva de procesos } \\
\text { internos } \\
\text { - Perspectiva de aprendizaje } \\
\text { y crecimiento }\end{array}$ & $\begin{array}{l}\text { Indicadores } \\
\text { financieros } \\
\text { Indicadores no } \\
\text { financieros o de } \\
\text { intangibles }\end{array}$ \\
\hline $\begin{array}{l}\text { 5. Método Tech Factor, } \\
\text { Dow Chemical (firma } \\
\text { de consultoría Arthur } \\
\text { D. Little, 1996) }\end{array}$ & $\begin{array}{l}\text { Metodología para la clasificación, } \\
\text { valoración y gestión de la cartera de } \\
\text { patentes de la empresa. }\end{array}$ & $\begin{array}{l}\text { - Capital humano } \\
\text { - Capital organizacional } \\
\text { - Capital cliente }\end{array}$ & $\begin{array}{l}\text { Indicadores } \\
\text { de intangibles } \\
\text { con impacto en } \\
\text { los resultados } \\
\text { organizativos }\end{array}$ \\
\hline $\begin{array}{l}\text { 6. El capital } \\
\text { Intelectual. } \\
\text { Technology Broker } \\
\text { (Annie Brooking, } \\
\text { 1997) }\end{array}$ & $\begin{array}{l}\text { Valoración del capital intelectual como } \\
\text { un servicio. "La valoración hace que } \\
\text { las cosas sean valiosas". El futuro es } \\
\text { inmaterial. }\end{array}$ & $\begin{array}{l}\text { - Activos de mercado } \\
\text { - Activos de propiedad } \\
\text { intelectual } \\
\text { - Activos de infraestructura } \\
\text { - Activos centrados en el } \\
\text { individuo }\end{array}$ & $\begin{array}{l}\text { Indicadores no } \\
\text { cuantitativos } \\
\text { Auditoría del capital } \\
\text { intelectual }\end{array}$ \\
\hline $\begin{array}{l}\text { 7. The Value Creation } \\
\text { Index (Johan Roos \& } \\
\text { Göran Roos, 1997) }\end{array}$ & $\begin{array}{l}\text { Es un modelo que se desarrolla, a partir } \\
\text { de las combinaciones de las diferentes } \\
\text { categorías clave de activos intangibles, } \\
\text { lo que evidencia el resultado de la } \\
\text { empresa en esas categorías y permite } \\
\text { también medir el impacto de los activos } \\
\text { intangibles en el valor de mercado de la } \\
\text { compañía. }\end{array}$ & $\begin{array}{l}\text { - Innovación } \\
\text { - Calidad } \\
\text { - Clientela } \\
\text { - Marcas } \\
\text { - Empleados } \\
\text { - Dirección } \\
\text { - Alianzas } \\
\text { - Tecnología } \\
\text { - Medio ambiente }\end{array}$ & $\begin{array}{l}\text { Índices de capital } \\
\text { intelectual, } \\
\text { que integran } \\
\text { los diferentes } \\
\text { indicadores en una } \\
\text { única medida }\end{array}$ \\
\hline $\begin{array}{l}\text { 8. Capital Intelectual } \\
\text { (Johan Roos, Nicola } \\
\text { C. Dragonetti, Göran } \\
\text { Roos, Leif Edvinsson, } \\
\text { 1997) }\end{array}$ & $\begin{array}{l}\text { El desarrollo y la influencia del } \\
\text { conocimiento no pueden ser actividades } \\
\text { separadas. La completa aplicación del } \\
\text { conocimiento es un objetivo en sí mismo } \\
\text { y significa desarrollar conocimiento } \\
\text { nuevo. }\end{array}$ & $\begin{array}{l}\text { - Capital humano } \\
\text { (competencia, actitud y } \\
\text { agilidad intelectual) } \\
\text { - Capital estructural } \\
\text { (relaciones, organización y } \\
\text { renovación y desarrollo) }\end{array}$ & $\begin{array}{l}\text { Indicadores de capital } \\
\text { humano y de capital } \\
\text { estructural }\end{array}$ \\
\hline $\begin{array}{l}\text { 9. Modelo de gestión } \\
\text { del conocimiento de } \\
\text { KPMG Consulting } \\
\text { (Beatriz Tejedor \& Ane } \\
\text { Aguirre, 1998) }\end{array}$ & $\begin{array}{l}\text { Su finalidad es la exposición clara y } \\
\text { práctica de los factores que condicionan } \\
\text { la capacidad de aprendizaje de una } \\
\text { organización, así como los resultados } \\
\text { esperados del aprendizaje. }\end{array}$ & $\begin{array}{l}\text { - Compromiso con la } \\
\text { visión de la organización } \\
\text { aprendedora. } \\
\text { - Comportamientos } \\
\text { y mecanismos de } \\
\text { aprendizaje a todos los } \\
\text { niveles. } \\
\text { - Desarrollo de las } \\
\text { infraestructuras } \\
\text { que condicionan el } \\
\text { funcionamiento de la } \\
\text { empresa } \\
\text { - Comportamiento de } \\
\text { personas y grupos, para } \\
\text { favorecer el aprendizaje. }\end{array}$ & $\begin{array}{l}\text { Factores de } \\
\text { aprendizaje } \\
\text { Factores que } \\
\text { condicionan los } \\
\text { resultados del } \\
\text { aprendizaje }\end{array}$ \\
\hline
\end{tabular}




\begin{tabular}{|c|c|c|c|}
\hline Modelo & Línea de argumentación & $\begin{array}{c}\text { Clasificación de } \\
\text { intangibles }\end{array}$ & Indicadores \\
\hline $\begin{array}{l}\text { 10. Modelo Intelect } \\
\text { (Euroforum, 1998) }\end{array}$ & $\begin{array}{l}\text { Pretende acercar el valor explicitado de } \\
\text { la organización a su valor de mercado } \\
\text { e informar sobre la capacidad de la } \\
\text { organización de generar resultados } \\
\text { sostenibles, mejoras constantes } \\
\text { y crecimiento a largo plazo. Está } \\
\text { estructurado en bloques, elementos e } \\
\text { indicadores. }\end{array}$ & $\begin{array}{l}\text { - Capital humano } \\
\text { - Capital estructural } \\
\text { - Capital relacional }\end{array}$ & $\begin{array}{l}\text { Indicadores de } \\
\text { presente y de futuro }\end{array}$ \\
\hline $\begin{array}{l}\text { 11. El método del } \\
\text { índice (CI) Intellectual } \\
\text { Capital Services, Ltd. } \\
\text { Londres (Johan Roos, } \\
\text { Leif Edvinsson \& } \\
\text { Göran Roos, 1998) }\end{array}$ & $\begin{array}{l}\text { Consolida todos los indicadores } \\
\text { individuales de capital intelectual } \\
\text { en un único índice no financiero, } \\
\text { al correlacionar sus cambios con } \\
\text { variaciones en el valor de mercado de la } \\
\text { compañía. }\end{array}$ & & $\begin{array}{l}\text { Combinación de } \\
\text { medidas monetarias } \\
\text { (de valor absoluto) } \\
\text { con medidas } \\
\text { porcentuales (de } \\
\text { eficiencia). Su } \\
\text { integración produce } \\
\text { un solo indicador } \\
\text { de CI. }\end{array}$ \\
\hline $\begin{array}{l}\text { 12. Modelo de } \\
\text { dirección estratégica } \\
\text { por competencias: } \\
\text { el capital intangible } \\
\text { (Eduardo Bueno- } \\
\text { Campos, 1998) }\end{array}$ & $\begin{array}{l}\text { Refleja los tres pilares básicos de la } \\
\text { dirección estratégica por competencias: } \\
\text { conocimientos, capacidades y actitudes y } \\
\text { valores; que constituyen la competencia } \\
\text { básica distintiva. }\end{array}$ & $\begin{array}{l}\text { - Capital organizativo } \\
\text { - Capital humano } \\
\text { - Capital tecnológico } \\
\text { - Capital relacional }\end{array}$ & $\begin{array}{l}\text { Indicadores de } \\
\text { competencias básicas } \\
\text { distintivas }\end{array}$ \\
\hline $\begin{array}{l}\text { 13. Knowledge } \\
\text { Management } \\
\text { Assessment Tool } \\
\text { (KMAT, 1998) }\end{array}$ & $\begin{array}{l}\text { Instrumento de evaluación y diagnóstico } \\
\text { construido sobre la base del modelo } \\
\text { de administración del conocimiento } \\
\text { organizacional. }\end{array}$ & $\begin{array}{l}\text { - Liderazgo } \\
\text { - Cultura } \\
\text { - Tecnología } \\
\text { - Medición }\end{array}$ & $\begin{array}{l}\text { Indicadores de } \\
\text { conocimiento } \\
\text { organizacional }\end{array}$ \\
\hline $\begin{array}{l}\text { 14. Modelo Nova } \\
\text { (Club de Gestión } \\
\text { del Conocimiento } \\
\text { y la Innovación } \\
\text { de la Comunidad } \\
\text { Valenciana, 1999) }\end{array}$ & $\begin{array}{l}\text { El objetivo del modelo es el de medir } \\
\text { y gestionar el capital intelectual en } \\
\text { las organizaciones; va a ser útil para } \\
\text { cualquier empresa, independientemente } \\
\text { de su tamaño. Se refiere a la gran } \\
\text { cantidad de activos intangibles que hacen } \\
\text { que la empresa crezca en un futuro y se } \\
\text { mantenga generando valor a sí misma y } \\
\text { contribuyendo al crecimiento sostenible } \\
\text { del ente económico y la sociedad. }\end{array}$ & $\begin{array}{l}\text { - Capital humano } \\
\text { - Capital organizativo } \\
\text { - Capital social } \\
\text { - Capital de innovación y de } \\
\text { aprendizaje }\end{array}$ & $\begin{array}{l}\text { Indicadores de } \\
\text { procesos dinámicos }\end{array}$ \\
\hline $\begin{array}{l}\text { 15. Modelo Andersen } \\
\text { (Arthur Andersen, } \\
\text { 1999) }\end{array}$ & $\begin{array}{l}\text { Hace énfasis en el conocimiento } \\
\text { como eje de la organización, tanto de } \\
\text { carácter individual como de carácter } \\
\text { organizacional. }\end{array}$ & $\begin{array}{l}\text { - Conocimiento personal } \\
\text { - Conocimiento } \\
\text { organizacional }\end{array}$ & $\begin{array}{l}\text { Flujo de información } \\
\text { valiosa. Indicadores } \\
\text { de captura y de } \\
\text { distribución de } \\
\text { conocimiento }\end{array}$ \\
\hline $\begin{array}{l}\text { 16. Proyecto Meritum } \\
\text { (2001) }\end{array}$ & $\begin{array}{l}\text { Proporciona un marco de referencia con } \\
\text { validez general para la identificación, } \\
\text { medición y control de los intangibles en } \\
\text { el seno de la empresa, determinantes de } \\
\text { su capacidad de creación de valor. }\end{array}$ & $\begin{array}{l}\text { - Capital humano } \\
\text { - Capital estructural } \\
\text { - Capital relacional }\end{array}$ & $\begin{array}{l}\text { Indicadores } \\
\text { financieros y no } \\
\text { financieros } \\
\text { Indicadores de } \\
\text { intangibles críticos }\end{array}$ \\
\hline
\end{tabular}


ANÁLISIS DESCRIPTIVO Y ECONOMÉtRICO A ACTIVOS INTANGIBLES / Z. RAMíREZ, A. Gómez / 119

\begin{tabular}{llll}
\hline \multicolumn{1}{c}{ Modelo } & \multicolumn{1}{c}{ Línea de argumentación } & $\begin{array}{c}\text { Clasificación de } \\
\text { intangibles }\end{array}$ & \multicolumn{1}{c}{ Indicadores } \\
\hline 17. Modelo estocástico & Herramienta (modelo estocástico) para la & - Capital humano & Indicadores \\
(Domingo Nevado- & estimación, determinación, predicción y & - Capital estructural & medidos en \\
Peña \& Víctor Raúl & gestión del capital intelectual, basados en & (capital procesos, capital & unidades monetarias \\
López-Ruiz, 2004) & el modelo de Skandia, con la adición de & relacional, capital & (indicadores \\
& los factores especulativos, de crisis y azar, & comunicacional y & absolutos), e índices \\
& propios del modelo estocástico. & capital de innovación o & porcentuales \\
& & desarrollo) & \\
& & Capital no explicitado & \\
& & & \\
\hline
\end{tabular}

Tabla 1. Contrastación modelos de valoración de intangibles

Fuente: elaboración propia

La anterior tabla resalta los esfuerzos de algunos académicos y profesionales, por generar propuestas de gestión de capital intelectual, al examinar temáticas de capital humano, capital estructural, capital relacional, capital organizativo, capital tecnológico, activos de mercado e individuales, entre otros; con una particularidad relativa a la necesidad de gestionar y controlar intangibles en las organizaciones y de abordar la temática con alternativas de medición. En los últimos tiempos, la literatura en la temática ha aumentado, lo que genera una diversidad y multiplicidad de opciones, desde su gestión y control. La contabilidad solo cuenta con herramientas regulativas que limitan el ejercicio de identificación y reconocimiento, con una consecuente limitación para la valoración y revelación de intangibles en los estados financieros.

\section{Evidencia empírica de intangibles relevantes}

Es importante mostrar la forma en que algunas erogaciones, como gastos, inversiones y otros, se convierten en estratégicas para la genera- ción de valor en las organizaciones y, por consiguiente, el incremento de la riqueza para sus propietarios. En el escenario de hoy, la dinámica de las salidas de caja para pagos de publicidad, investigación y desarrollo, capacitación del talento humano, bases de datos o tecnológicas hacen parte de la cotidianidad de los negocios que pretenden tener ciertas ventajas competitivas y comparativas. La forma en que se reconocen o se muestran en la información contable, a partir de métodos o metodologías existentes, podrían convertirse en un instrumento clave para estimular el mercado y a los usuarios de esta información.

Dispersos en la literatura económica, financiera y contable, hay numerosos foros, iniciativas e instituciones promovidos por grandes corporaciones empresariales que evidencian una creciente preocupación por la valoración y el reporte de intangibles en el ámbito empresarial. Entre las iniciativas más destacadas, están "el Instituto de Análisis de Intangibles, la Asociación de Marcas Renombradas, el Foro de Reputación Corporativa, el Reputation Institute, el Global Reporting Initiative, GRI” (Salinas, 2007, p. 49). También se ha evidenciado la 
creciente importancia de los intangibles en el tiempo. "Uno de los más difundidos es el estudio realizado por el economista John Kendrick en 1994, en el que se evidencia la creciente relevancia de los activos intangibles, y en particular la marca en la estructura patrimonial de las empresas" (Salinas, 2007, p. 50).

Inicialmente, no se había podido determinar con certeza la relevancia o consistencia de la relación existente entre los gastos de investigación y desarrollo (I+D), los gastos en publicidad, en datos de proveedores y clientes, entre otros intangibles, y su contribución a la generación de utilidades en las organizaciones. Pero recientes investigaciones por medio de entrevistas y análisis (cuantitativo y cualitativo) de información financiera, han detectado una relación positiva entre una futura generación de beneficios (rentabilidad) e inversiones, no solo en publicidad, sino también en $\mathrm{I}+\mathrm{D}$, marcas y patentes, satisfacción de clientes y proveedores. Sin embargo, la gestión de los intangibles comprende identificarlos, evaluar sus nexos con el valor actual y futuro de la empresa, medir su valor, descubrir actividades intangibles y, por último, ser capaz de administrar eficientemente esas actividades. Para firmas jóvenes e innovadoras en ambientes altamente competitivos (farmacéuticas, comunicaciones inalámbricas, servicios de internet, etc.) los activos más importantes a largo término son los intangibles como el conocimiento de sus empleados, tecnología en desarrollo, arreglos de manufactura, marketing y sistemas de distribución, que no aparecen en los extractos financieros (Beverley A. Brennan, 1992, en Cañibano-Calvo \& Sánchez-Muñoz, 2004). Algunos gastos, inver- siones y erogaciones en intangibles muestran evidencias de su relación positiva con el valor de las organizaciones, como investigación y desarrollo $(\mathrm{I}+\mathrm{D})$, publicidad, inversión en patentes, marcas y su registro, gastos en satisfacción al cliente, e inversiones en talento humano. Estas erogaciones y su relación positiva con la generación de riqueza evidencian la necesidad apremiante de incorporarlas adecuadamente en la información contable y financiera.

\subsection{Investigación y desarrollo (I+D)}

Siguiendo a Theodore Sougiannis (1994), en Leandro Cañibano-Calvo \& María Paloma Sánchez-Muñoz (2004), se demuestra que las ganancias ajustadas al gasto en $\mathrm{I}+\mathrm{D}$ son un reflejo de las inversiones realizadas en este rubro. Sougiannis sostiene que un incremento en I+D conduce a un incremento de las utilidades en un período de 7 años. También afirma que si las inversiones en $\mathrm{I}+\mathrm{D}$ resultan en incrementos de beneficios futuros, debería haber una relación positiva y significante entre los precios de las acciones y los gastos en $\mathrm{I}+\mathrm{D}$ y los dividendos y los incrementos en inversiones en I+D. Los resultados en estos estudios sugieren que las inversiones en I+D están asociadas al valor de mercado de las compañías y que, por tanto, deberían capitalizarse y amortizarse durante la vida económica de la compañía, que comúnmente difiere en industrias y empresas, con efectos importantes en el reconocimiento contable de esas erogaciones (inversiones o gastos) y, por consiguiente, en las utilidades, dividendos, patrimonio y participaciones minoritarias, entre otros aspectos financieros. Sin embargo, es importante contemplar las limitaciones que puede 
tener la consistencia de los resultados que se reporten de una u otra forma (activos o gastos), ya que considerar las inversiones en $\mathrm{I}+\mathrm{D}$ como único aspecto generador de valor en una organización sería un error, pues se pueden presentar otros factores encubiertos en los gastos, que también podrían explicar el aumento de valor de las acciones en el mercado.

\subsection{Publicidad}

Inicialmente, algunos investigadores encontraron que el impacto de la publicidad no era a largo plazo y que esta se limitaba únicamente a un período de dos años. Por lo tanto, no parece haber una base lógica para la capitalización de gastos publicitarios. Sin embargo, A. Rashad Abdel-Khalik (1975), en Manuel García-Ayuso Covarsí, María Paloma Sánchez-Muñoz y Leandro Cañibano-Calvo (2004), indica la efectividad a largo plazo de la publicidad, en las industrias de medicamentos y cosméticos; de igual forma, Keith W. Chauvin y Mark Hirschey (1993), en Manuel García-Ayuso Covarsí, María Paloma Sánchez-Muñoz y Leandro Cañibano-Calvo (2004), determinaron en su estudio, que las inversiones o gastos en publicidad tienen grandes, positivos y consistentes influencias en el valor de las compañías, aunque indican que el efecto en las grandes empresas es mucho mayor que en las pequeñas.

\subsection{Patentes}

Estudios realizados para determinar la importancia del valor de las patentes, demuestran que, aunque ellas no tienen mucho poder aclaratorio sobre las inversiones en $\mathrm{I}+\mathrm{D}$, pueden transmitir información con respecto a las mediciones en
I+D. La evidencia encontrada en estos estudios sugiere que tanto las patentes como las pruebas de patentes se relacionan constantemente con el valor de mercado de las compañías.

\subsection{Marcas y marcas registradas}

Las marcas son nombres y símbolos que se usan para identificar bienes o servicios suministrados por una entidad y que se diferencian de aquellos de sus competidores. La propiedad de una marca que es atractiva para los clientes, le permite al vendedor obtener un margen más alto de bienes o servicios que son similares a los de la competencia. Por lo tanto, las marcas se pueden considerar un intangible, cuyo valor es más alto que el reportado en el balance. Se evidencia entonces, que dos productos iguales pueden ser vendidos con precios diferentes, gracias al valor de su marca.

\subsection{Satisfacción del cliente}

Aunque en la actualidad no hay una clara evidencia de la relación entre la satisfacción del cliente y el desempeño financiero de una empresa, los clientes pagarían un precio más alto (y, por lo tanto, la empresa recibiría utilidades más altas) cuando estén satisfechos con los productos y servicios suministrados por la compañía. Así que el desempeño financiero en el futuro y el valor de mercado de una empresa tienden a ser más altos con la satisfacción de sus clientes, producto del respaldo que ellos perciben de la organización.

\subsection{Talento humano}

Una organización que posee un grupo de empleados mejor capacitados, obtiene más altos 
beneficios que aquellas organizaciones cuyos empleados están menos capacitados para realizar las labores de la empresa. Por lo tanto, debe haber una relación entre el valor de las compañías y la calidad de su recurso humano. Hay varios estudios empíricos que han intentado establecer una relación constante entre las diferentes mediciones de valor de los recursos humanos y el valor de mercado de las compañías. Bo Hansson (1997) encontró que las compañías con un amplio conocimiento arrojaron un promedio más alto en sus utilidades que aquellas en las cuales el conocimiento de sus empleados era menos importante.

Con los anteriores ejemplos a manera de evidencia, y a los que podrían sumarse el estilo de la gerencia, el compromiso con el medio ambiente y/o la calidad, el buen nombre, el know how, el crédito mercantil, la capacidad organizativa, el aprendizaje organizacional, el copyright, los convenios y alianzas, entre otros; y para poder realizar una descripción detallada de las prácticas contables llevadas a cabo en la realidad comercial de la ciudad de Popayán, se propuso metodológicamente indagar con la metodología Delphi a expertos (propietarios de empresas, procesadores de información financiera y usuarios de información financiera) sobre la temática de los intangibles, sus percepciones y prácticas. También se propuso mediante el estudio de casos indagar de manera más detallada y profunda, la dinámica empresarial alrededor de los intangibles, su identificación, medición, valoración y revelación, en la información contable.

\section{Metodología}

Para este apartado, que tiene como objetivo rastrear el grado de conocimiento, definición y tipologías de intangibles desde la óptica de propietarios, procesadores (contadores públicos) y usuarios de información financiera en empresas comerciales, industriales y de servicios para Popayán, se realizó un trabajo de evidencia empírica de carácter cualitativo que aborda dos metodologías: la metodología Delphi y el estudio de casos. Cristina Chaminade, Pedro Luis Sánchez-Ortín y Carmen Gloria Escobar (1999) resaltan que en este estado de escasez informativa, para la investigación en materia de intangibles, las técnicas de investigación cualitativas se convierten en las herramientas de estudio más adecuadas.

En la fase exploratoria, como este estudio, el análisis Delphi y el estudio de casos posibilitan la recolección de un buen volumen de información cualitativa y cuantitativa del fenómeno que será analizado.

\subsection{Metodología Delphi}

Esta herramienta de investigación para obtener información esencialmente cualitativa, se basa en la interrogación a expertos ${ }^{2}$ con la ayuda de

\footnotetext{
2 En este estudio se consideran expertos aquellos agentes que preparan la información contable y aquellos que hacen uso de ella y que, por lo tanto, a pesar de no tener experticia académica e investigativa en la temática, conforman el grupo focal de estudio sobre la temática de los intangibles, ante la poca información y por lo tanto opinión de este tipo de individuos. Así, los expertos en la preparación de información son los contadores públicos de las empresas; los expertos en el uso interno de la información son los propietarios; y los expertos en el uso externo de la información son los acreedores financieros.
} 
cuestionarios sucesivos, para poner de manifiesto las convergencias de opiniones y deducir los eventuales consensos. La consulta al grupo de expertos es individual por medio de la interacción sucesiva de un cuestionario, apoyado por los resultados promedio de la ronda anterior para generar convergencia de opiniones. La calidad de los resultados que se obtienen al aplicar esta metodología dependerá de la elaboración de los cuestionarios y de la elección de los expertos consultados. Este método contiene cuatro fases de aplicación:

\section{- Definición de los objetivos}

- Selección de los expertos (dimensión cualitativa y dimensión cuantitativa)

- Exploración y lanzamiento de los cuestionarios

- Exploración de resultados (análisis)

En la primera fase - la definición de objetivos-, se decidió que el objetivo general de esta metodología es identificar el grado de conocimiento, apropiación y utilidad de los intangibles. Para la segunda fase - la selección de los expertos-, se realizó una división en tres grupos definidos con el fin de obtener resultados precisos para lograr el objetivo principal así: 1. propietarios y/o representantes legales de empresas, 2. procesadores de información (contadores públicos) y 3. usuarios de la información contable (acreedores financieros).

En la exploración y lanzamiento de los cuestionarios - tercera fase-, se escogió una muestra intencional de 45 empresas, 10 de ellas pertenecientes a la red de software y 35 del sector comercial, para ubicar la muestra de propie- tarios y procesadores de información. Esto se hizo con el fin de escoger empresas pertenecientes a la nueva economía en la ciudad de Popayán, debido a que el proyecto exige que las empresas escogidas en la muestra estén inmersas en las dinámicas de la economía de la información, del conocimiento y/o de prestación de servicios tecnológicos. Para conformar la muestra de usuarios de información se seleccionaron aleatoria e intencionadamente 50 usuarios financieros ${ }^{3}$ (analistas de cartera y analistas de inversiones), con la finalidad de conocer la utilidad que ellos les dan a los intangibles, y qué tan importantes son, cuando se trata de analizar información contable y financiera de empresas en las que pudieran tener algún interés (créditos, inversiones, etc.). Esta fase se resume en la tabla 2.

Para la última fase concerniente a la exploración de resultados, estos fueron procesados y/o sistematizados, con ayuda del programa estadístico SPSS y cada una de las respuestas a las preguntas fue analizada de acuerdo con los objetivos planteados.

\subsection{Estudio de casos}

Esta técnica de investigación se caracteriza por centrarse en la pregunta de investigación y en el objetivo propuesto. Las características que definen el estudio de casos no son la técnica de recolección de datos o la naturaleza de la información utilizada, sino el tipo de pregunta de investigación, el grado de control sobre el fenómeno analizado y el horizonte temporal.

\footnotetext{
3 Se seleccionan aleatoriamente, ya que en la ciudad de Popayán hay una población de analistas de cartera y analistas de inversiones en un número mayor a 50 personas. Se considera que esta cantidad es una muestra representativa, para la aplicación de cuestionarios.
} 


\begin{tabular}{|c|c|c|c|c|}
\hline $\begin{array}{l}\text { Tipo de } \\
\text { experto }\end{array}$ & $\begin{array}{l}\text { Objetivo de } \\
\text { la encuesta }\end{array}$ & Preguntas & $\begin{array}{c}\text { Categorías conceptuales de } \\
\text { la empresa }\end{array}$ & Muestra \\
\hline $\begin{array}{l}\text { Propietario y/o } \\
\text { representante legal }\end{array}$ & $\begin{array}{l}\text { Grado de } \\
\text { conocimiento, } \\
\text { apropiación y } \\
\text { utilidad acerca de } \\
\text { los intangibles en } \\
\text { la empresa }\end{array}$ & 13 & $\begin{array}{l}\text { Conocimiento del término intangible } \\
\text { Clasificación de los intangibles } \\
\text { Concepto de intangible } \\
\text { Identificación de intangibles } \\
\text { Reconocimiento contable } \\
\text { Métodos de medición y valoración } \\
\text { Revelación de intangibles en la } \\
\text { información financiera } \\
\text { Valor dado a los intangibles }\end{array}$ & $\begin{array}{l}10 \text { empresas de la } \\
\text { red del software } \\
\text { y } 35 \text { empresas } \\
\text { comerciales y de } \\
\text { servicios }\end{array}$ \\
\hline $\begin{array}{l}\text { Procesador de } \\
\text { información } \\
\text { contable y } \\
\text { financiera }\end{array}$ & $\begin{array}{l}\text { Grado de } \\
\text { conocimiento, } \\
\text { apropiación y } \\
\text { utilidad acerca de } \\
\text { los intangibles en } \\
\text { la empresa }\end{array}$ & 12 & $\begin{array}{l}\text { Conocimiento del término intangible } \\
\text { Clasificación de los intangibles } \\
\text { Concepto de intangible } \\
\text { Identificación de intangibles } \\
\text { Reconocimiento contable } \\
\text { Métodos de medición y valoración } \\
\text { Revelación de intangibles en la } \\
\text { información financiera } \\
\text { Valor dado a los intangibles }\end{array}$ & $\begin{array}{l}10 \text { empresas de la } \\
\text { red del software } \\
\text { y } 35 \text { empresas } \\
\text { comerciales y de } \\
\text { servicios }\end{array}$ \\
\hline $\begin{array}{l}\text { Usuario de la } \\
\text { información } \\
\text { financiera }\end{array}$ & $\begin{array}{l}\text { Grado de } \\
\text { conocimiento, } \\
\text { apropiación y } \\
\text { utilidad acerca de } \\
\text { los intangibles en } \\
\text { la empresa }\end{array}$ & 8 & $\begin{array}{l}\text { Conocimiento del término intangible } \\
\text { Clasificación de los intangibles } \\
\text { Concepto de intangible } \\
\text { Identificación de intangibles } \\
\text { Revelación e importancia de los } \\
\text { intangibles }\end{array}$ & $\begin{array}{l}50 \text { entidades } \\
\text { financieras y } \\
\text { usuarios externos }\end{array}$ \\
\hline
\end{tabular}

Tabla 2. Diseño metodológico de instrumentos para construcción empírica de evidencias en la temática de intangibles Fuente: elaboración propia

Para el desarrollo de esta metodología, se realizó un trabajo inductivo con el objetivo de estudiar cuatro casos especiales de empresas comerciales, de servicios de transformación y de tecnología (producción de software). El objetivo que se persigue es obtener el grado de conocimiento, apropiación y utilidad de los intangibles en cada organización. La muestra en este caso se escogió intencionalmente, ya que se necesitaban empresas que pertenecieran a la nueva economía 4 .

\footnotetext{
4 Modelo productivo y discurso cultural, formado por un conjunto de economías: economía globalizada, economía de la información y una economía en red (Berardi, 2003, p. 20).
} 


\section{Análisis de resultados. Metodología Delphi}

Esta metodología no tiene como objetivo validar información, sino recolectar un consenso de opiniones de "expertos", como ya se definieron anteriormente, y que tienen una relación directa con la temática de los intangibles: propietarios, procesadores y usuarios de información contable y financiera. Para efectos de análisis y coherencia, se hizo una consolidación de los resultados arrojados por las encuestas realizadas y se propuso la siguiente clasificación:

\subsection{Conocimiento del término intangible} Para abordar este ítem, solo fueron indagados los propietarios de las empresas y los usuarios de la información, ya que se parte de que quienes procesan información financiera no son ajenos a esta terminología. A continuación, se muestran los resultados obtenidos al realizar la pregunta de conocimiento del término intangible:

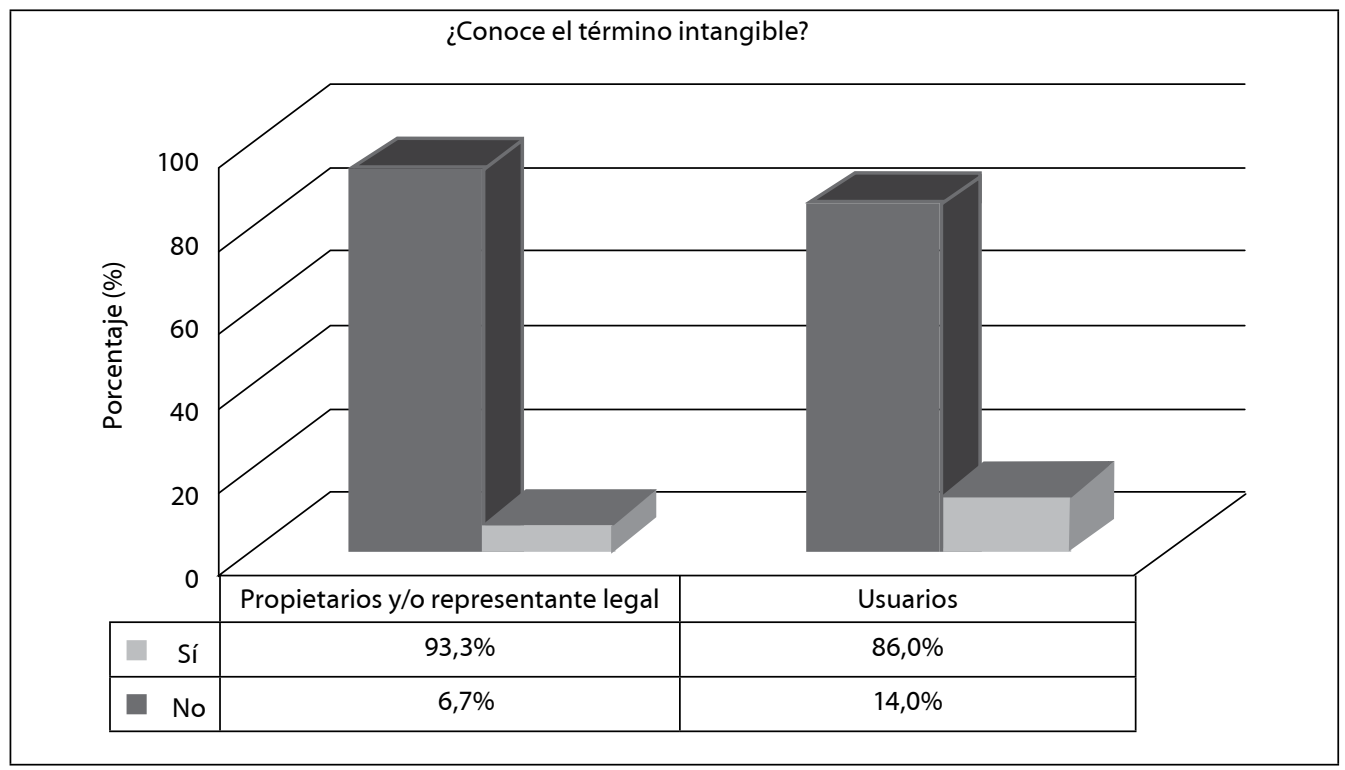

Figura 1. Grado de conocimiento del término intangible Fuente: elaboración propia

Estos resultados indican que el término intangible es en su mayoría conocido por propietarios $(93,3 \%)$ y usuarios de información $(86,0 \%)$, por lo cual las indagaciones acerca de las diversas tipologías y/o clasificaciones pueden tener una alta confiabilidad.

\subsubsection{Clasificación de los intangibles}

En este apartado se indagó acerca de las categorías o posibles clasificaciones y/o adjetivos, que podrían tomar los intangibles. Los tres tipos de expertos (propietarios, procesadores y usuarios) respondieron de manera consolidada, como se muestra en la tabla 3: 


\begin{tabular}{lcccccccccccc}
\hline & \multicolumn{4}{c}{ Propietarios } & \multicolumn{4}{c}{ Procesadores } & \multicolumn{4}{c}{ Usuarios } \\
\cline { 2 - 13 } & Sí & $\%$ & No & $\%$ & Sí & \% & No & $\%$ & Sí & $\%$ & No & $\%$ \\
\hline Activo & 22 & 48,89 & 23 & 51,11 & 35 & 77,8 & 10 & 22,2 & 27 & 54 & 23 & 46 \\
Pasivo & & & & & 1 & 2,2 & 44 & 97,8 & 7 & 14 & 43 & 86 \\
Patrimonio & 15 & 33,33 & 30 & 66,67 & 12 & 26,7 & 33 & 73,3 & 10 & 20 & 40 & 80 \\
Ingreso & & & & & 1 & 2,2 & 44 & 97,8 & 8 & 16 & 42 & 84 \\
Costo & 6 & 13,33 & 39 & 86,67 & 1 & 2,2 & 44 & 97,8 & 6 & 12 & 44 & 88 \\
Actividad & & & & & 1 & 2,2 & 44 & 97,8 & 9 & 18 & 41 & 82 \\
Recurso & 15 & 33,3 & 30 & 66,7 & 5 & 11,1 & 40 & 88,9 & 6 & 12 & 44 & 88 \\
Todas las anteriores & 7 & 15,56 & 38 & 84,44 & 2 & 4,4 & 43 & 95,6 & 7 & 14 & 43 & 86 \\
\hline
\end{tabular}

Tabla 3. Criterio de clasificación de los intangibles

Fuente: elaboración propia

Los resultados muestran una inclinación tanto de propietarios, como procesadores y usuarios de información financiera, hacia la clasificación de los intangibles como un activo (supera el 50\% de la muestra encuestada en cada caso), seguida de la indicación de patrimonio. Se asume entonces, que las clasificaciones de pasivo, ingreso, costo, actividad y/o recurso son sustantivos poco comunes que se relacionan con el adjetivo intangible. Además, los procesadores de información (auxiliares contables y/o contadores públicos), debido a su formación en el área financiera, designan el adjetivo intangible en un gran porcentaje para los activos (77,8\%), en una mayor proporción que los demás expertos encuestados (propietarios y usuarios).

\subsubsection{Concepto de intangible}

Con una pregunta cerrada se intenta mostrar cuál es el concepto que más se acerca al criterio de identificación de los intangibles, para cada uno de los expertos (propietarios de empresas, procesadores y usuarios de información financiera). Así, las opciones presentadas a los expertos y las respuestas dadas a las mismas se consolidan en la tabla 4:

\begin{tabular}{|c|c|c|c|c|c|c|}
\hline Criterios de asociación & Propietarios & $\%$ & Procesadores & $\%$ & Usuarios & $\%$ \\
\hline $\begin{array}{l}\text { No son perceptibles a los } \\
\text { sentidos }\end{array}$ & 7 & 15,6 & 4 & 8,9 & 5 & 10 \\
\hline No tienen propiedades físicas & 4 & 8,9 & 0 & 0,0 & 12 & 24 \\
\hline $\begin{array}{l}\text { Aquello que no vemos y que } \\
\text { no podemos tocar, pero que le } \\
\text { genera valor a la empresa }\end{array}$ & 20 & 44,4 & 24 & 53,4 & 33 & 66 \\
\hline $\begin{array}{l}\text { Puede generar flujo de efectivo } \\
\text { sin tener presencia física }\end{array}$ & 12 & 26,7 & 6 & 13,3 & 0 & 0 \\
\hline Ninguna de las anteriores & 1 & 2,2 & 1 & 2,2 & 0 & 0 \\
\hline Todas las anteriores & 1 & 2,2 & 10 & 22,2 & 0 & 0 \\
\hline Total & 45 & 100,0 & 45 & 100,0 & 50 & 100 \\
\hline
\end{tabular}

Tabla 4. Concepto con el que se identifica un intangible Fuente: elaboración propia 
Los resultados de la tabla 4 demuestran que el concepto de intangible que más se acerca a la concepción de propietarios, procesadores y usuarios de información es "aquello que no vemos y que no podemos tocar, pero que le genera valor a la empresa"; del conjunto de expertos, los usuarios de la información, en su mayoría (66\%), se inclinan por este concepto. Además, es pertinente hacer un análisis a las respuestas de los propietarios de empresas, que distribuyen el concepto en dos grupos: el 44,4\% aborda el concepto de "aquello que no vemos y que no podemos tocar, pero que le genera valor a la empresa"; pero el 26,7\% se inclina por el concepto de aquello que puede generar flujo de efectivo sin tener presencia física. Las respuestas de los propietarios están menos concentradas y más dispersas que las de procesadores y usuarios de información, lo que indicaría que también pueden tener el concepto algo difuso y no ser claro en el momento de identificar o reconocer intangibles.

\subsubsection{Identificación de intangibles}

Como punto de partida para demostrar la capacidad intuitiva de identificar "intangibles" y su multiplicidad de percepciones, se propone mostrar los resultados de una pregunta abierta, realizada tanto a procesadores de información como a propietarios de las empresas ${ }^{5}$, pues se da libertad para ejemplificar intangibles presentes en las organizaciones. Y el resultado se muestra en la tabla 5:

\begin{tabular}{ll}
\hline \multicolumn{1}{c}{ Procesadores de información } & $\begin{array}{c}\text { Propietarios y/o representantes } \\
\text { legales }\end{array}$ \\
\hline $\begin{array}{l}\text { Good will, marcas formadas, patentes adquiridas, derechos } \\
\text { de leasing, crédito mercantil, know how, good will adquirido, } \\
\text { marcas corporativas, conocimiento, tratamiento de los }\end{array}$ & $\begin{array}{l}\text { Buen nombre, good will, conocimiento, nombre } \\
\text { del establecimiento, acreditación, servicio al } \\
\text { cliente, capacitación, marcas, venta por catálogo, }\end{array}$ \\
$\begin{array}{l}\text { lientes, acreditación del negocio, lugar donde se desarrollan } \\
\text { abicación de la empresa, tecnología, bases de datos, manejo }\end{array}$ & $\begin{array}{l}\text { rapidez, conocimientos, amabilidad, calidad del } \\
\text { del pervicio, seguros, procesos, publicidad, tecnología, }\end{array}$ \\
$\begin{array}{l}\text { capacitación, publicidad, calidad del servicio, diseño de software, }, \\
\text { procedimientos, metodologías y procesos. }\end{array}$ & $\begin{array}{l}\text { accesibilidad al negocio, manejo administrativo, } \\
\text { clienodelono de gestión, metodologías, la }\end{array}$ \\
\hline
\end{tabular}

Tabla 5. Ejemplos de intangibles en las organizaciones Fuente: elaboración propia

Así, se evidencia la capacidad intuitiva, tanto de los propietarios como de los procesadores de información, para ejemplificar una gran gama de artefactos en las organizaciones, que se asocian con los intangibles, como una forma de demostrar que cualquier tipo de negocio y/o actividad económica es susceptible de crearlos,
5 No se aplica esta pregunta a los usuarios de la información financiera, ya que la identificación, reconocimiento, medición, valoración y revelación de los intangibles en la información contable es propia de los procesadores de información y responsabilidad de los propietarios de las organizaciones. Los usuarios deben tener habilidad para la lectura, uso y comprensibilidad de la información y no para su preparación. 
procesarlos, adquirirlos y/o incorporarlos a la vida empresarial.

Además de lo anterior, se indaga a los tres tipos de expertos (propietarios, procesadores usuarios de información) acerca de la asociación de los intangibles con un listado cerrado de opciones, para considerar cuáles ítems se identifican y/o cumplen las condiciones para ser considerados como intangibles, y en qué proporción. Las opciones mostradas en la lista cerrada y los resultados para cada tipo de experto, se muestran en la tabla 6 :

\begin{tabular}{|c|c|c|c|c|c|c|c|c|c|c|c|c|}
\hline & \multicolumn{4}{|c|}{ Propietarios } & \multicolumn{4}{|c|}{ Procesadores } & \multicolumn{4}{|c|}{ Usuarios } \\
\hline & Sí & $\%$ & No & $\%$ & Sí & $\%$ & No & $\%$ & Sí & $\%$ & No & $\%$ \\
\hline Marcas corporativas & 21,0 & 46,7 & 24,0 & 53,3 & 32,0 & 71,1 & 13,0 & 28,9 & 26,0 & 52,0 & 24,0 & 48,0 \\
\hline Marcas de productos & 15,0 & 33,3 & 30,0 & 66,7 & 33,0 & 73,3 & 12,0 & 26,7 & 34,0 & 68,0 & 16,0 & 32,0 \\
\hline Copyright & 6,0 & 13,3 & 39,0 & 86,7 & 7,0 & 15,6 & 38,0 & 84,4 & 22,0 & 44,0 & 28,0 & 56,0 \\
\hline Derechos de diseño & 11,0 & 24,4 & 34,0 & 75,6 & 25,0 & 55,6 & 20,0 & 44,4 & 21,0 & 42,0 & 29,0 & 58,0 \\
\hline Patentes & 13,0 & 28,9 & 32,0 & 71,1 & 28,0 & 62,2 & 17,0 & 37,8 & 28,0 & 56,0 & 22,0 & 44,0 \\
\hline $\begin{array}{l}\text { Fidelización de la } \\
\text { clientela }\end{array}$ & 19,0 & 42,2 & 26,0 & 57,8 & 23,0 & 51,1 & 22,0 & 48,9 & 14,0 & 28,0 & 36,0 & 72,0 \\
\hline $\begin{array}{l}\text { Good will (buen } \\
\text { nombre) }\end{array}$ & 33,0 & 73,3 & 12,0 & 26,7 & 42,0 & 93,3 & 3,0 & 6,7 & 45,0 & 90,0 & 5,0 & 10,0 \\
\hline Capacitación & 17,0 & 37,8 & 28,0 & 62,2 & 19,0 & 42,2 & 26,0 & 57,8 & 13,0 & 26,0 & 37,0 & 74,0 \\
\hline $\begin{array}{l}\text { Publicidad, } \\
\text { promoción y } \\
\text { propaganda }\end{array}$ & 17,0 & 37,8 & 28,0 & 62,2 & 7,0 & 15,6 & 38,0 & 84,4 & 13,0 & 26,0 & 37,0 & 74,0 \\
\hline Convenios-alianzas & 13,0 & 28,9 & 32,0 & 71,1 & 10,0 & 22,2 & 35,0 & 77,8 & 10,0 & 20,0 & 40,0 & 80,0 \\
\hline Estilo gerencial & 17,0 & 37,8 & 28,0 & 62,2 & 18,0 & 40,0 & 27,0 & 60,0 & 15,0 & 30,0 & 35,0 & 70,0 \\
\hline $\begin{array}{l}\text { Ubicación del } \\
\text { negocio }\end{array}$ & 23,0 & 51,1 & 22,0 & 48,9 & 31,0 & 68,9 & 14,0 & 31,1 & 20,0 & 40,0 & 30,0 & 60,0 \\
\hline Ventas & 7,0 & 15,6 & 38,0 & 84,4 & 3,0 & 6,7 & 42,0 & 93,3 & 21,0 & 42,0 & 29,0 & 58,0 \\
\hline
\end{tabular}

Tabla 6. Asociación y/o identificación de intangibles

Fuente: elaboración propia

Los datos relacionados en la tabla 6 evidencian una clara dispersión de conceptos relacionados con la identificación de los intangibles. Según la lista presentada, los ítems que muestran una clara y real asociación con el término intangible y denotan el cumplimiento de las condiciones para considerarse como tal, son el good will (73\%, propietarios; 93\%, procesadores; 90\%, usuarios), las marcas tanto corporativas (46\%, propietarios;
$71 \%$, procesadores; $52 \%$, usuarios) como de productos (33\%, propietarios; $73 \%$, procesadores; $68 \%$, usuarios), y la ubicación del negocio (51\%, propietarios; 69\%; procesadores; 40\%, usuarios).

De la misma forma, y según la opinión de los expertos consultados, lo que menos se asocia con el término y no podría entonces cumplir cabalmente las condiciones para identificarse como tal, serían las ventas, el 
copyright, la publicidad, la propaganda y la promoción. Por ello, se generó una pregunta abierta, dirigida a propietarios de empresas y procesadores de información financiera, para ratificar el criterio de identificación en las actividades empresariales. Así, se les preguntó cuáles intangibles de los enunciados en la lista de la tabla 6, se identifican en las organizaciones de las que son propietarios y/o procesadores de información financiera. Los resultados fueron los siguientes:

\begin{tabular}{|c|c|}
\hline $\begin{array}{l}\text { Procesadores de } \\
\text { información }\end{array}$ & $\begin{array}{c}\text { Propietarios y/o } \\
\text { representantes } \\
\text { legales }\end{array}$ \\
\hline - Good will & - Ubicación del negocio \\
\hline - Ubicación & - Buen nombre \\
\hline - Marcas & - Good will \\
\hline - Buen nombre & $\begin{array}{l}\text { - Fidelización de los } \\
\text { clientes }\end{array}$ \\
\hline - Derechos de diseño & - Marcas corporativas \\
\hline - Estilo gerencial & - Capacitación \\
\hline $\begin{array}{l}\text { - Fidelización de la } \\
\text { clientela }\end{array}$ & - Ventas \\
\hline - Patentes & - Estilo gerencial \\
\hline - Clientela & - Publicidad \\
\hline - Capacitación & - Diseños y procesos. \\
\hline - Convenios & - Marcas de productos \\
\hline - Publicidad & \\
\hline - Ventas & \\
\hline - Copyright & \\
\hline
\end{tabular}

Tabla 7. Intangibles identificados en las organizaciones Fuente: elaboración propia

Lo anterior ratifica que hay muchos conceptos asociados a intangibles, que también son identificados de forma dispersa en la actividad empresarial, tanto por los propietarios como por los procesadores de información financiera. Es necesario además, mostrar los resultados de tres preguntas efectuadas a los propietarios de las organizaciones y que indagan acerca del grado de identificación de los intangibles con los conocimientos y habilidades de los empleados, y del gasto y/o inversión en capacitación. Esto pretende mostrar la importancia ponderada en el reconocimiento de intangibles asociados al capital humano.

Para el 87\% de los propietarios, tanto los conocimientos como las habilidades de los empleados son susceptibles de ser reconocidos como intangibles. Además, se incorporó una pregunta abierta para indagar acerca de la explicación a esta respuesta: el 44\% de la muestra opina que se explica en la medida en que esos conocimientos y habilidades de los empleados generan confianza al cliente, el 31\% de la muestra dice que generan mejoramiento de procesos, el 4\% dice que generan ingreso al buscar la satisfacción del comprador.

De la misma forma, se indagó a los propietarios acerca de la categoría en la que clasifican las capacitaciones realizadas a los empleados. Los resultados se muestran en la figura 3:

Las respuestas dadas por los propietarios de las empresas demuestran que no hay consenso acerca de la forma de clasificar las erogaciones, gastos y/o inversiones en capacitación, que se realizan en las organizaciones, dirigidas a los empleados. Se asocia en su mayoría con el criterio de inversión $(55,56 \%)$ y con el de activo $(31,11 \%)$, a pesar de que el reconocimiento contable en registros y estados financieros no revele esta posición. 
¿Considera que los conocimientos y habilidades de los empleados son intangibles?

No

$13,3 \%$

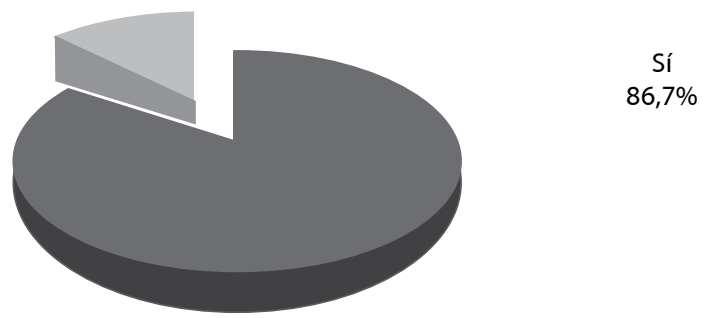

Figura 2. Asociación de conocimientos y habilidades de los empleados con los intangibles Fuente: elaboración propia

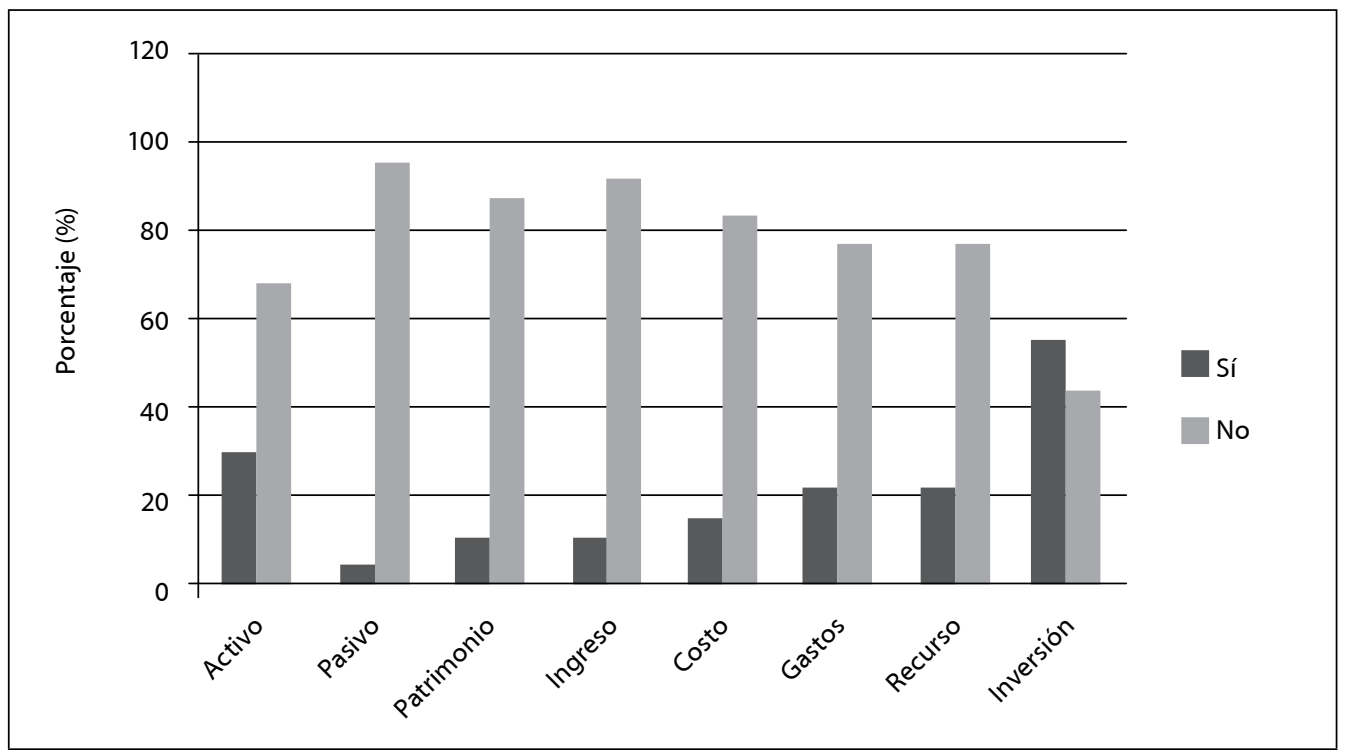

Figura 3. Criterio de clasificación para el rubro capacitación. Propietarios Fuente: elaboración propia

\subsubsection{Reconocimiento contable de los intangibles en las organizaciones}

A efectos de abordar no solo la etapa de conceptualización, clasificación e identificación, se hace necesario indagar acerca del reco- nocimiento contable. Dicha indagación se efectúa únicamente a los procesadores de información financiera, quienes son los responsables de dicho proceso en las organizaciones. 


\section{ANÁLISIS DESCRIPTIVO Y ECONOMÉtRICO A ACTIVOS INTANGIBLES / Z. RAMÍrEz, A. Gómez / 131}

\section{¿Están relacionados contablemente los intangibles identificados en las empresas?}

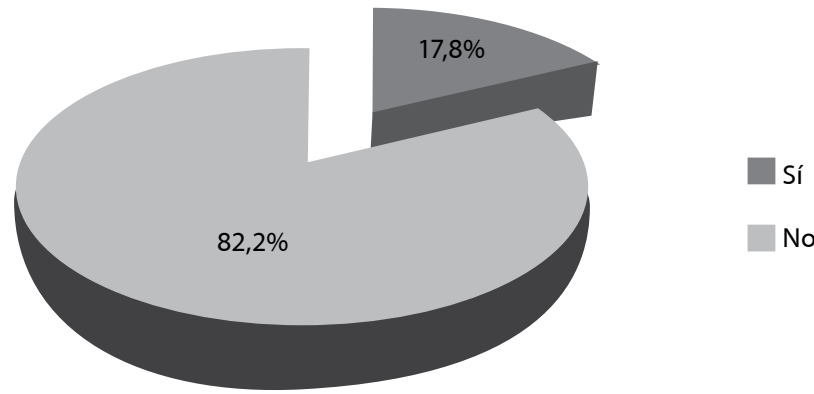

Figura 4. Reconocimiento contable de los intangibles Fuente: elaboración propia

El anterior resultado demuestra empíricamente que, a pesar del conocimiento del término intangible y su respectiva asociación a una diversidad de términos empresariales, dentro y fuera de las organizaciones, el $82 \%$ de los procesadores de información indica que no se reconocen contablemente. Adicionalmente, se pregunta si la empresa ha registrado y/o contabilizado intangibles formados internamente, con la finalidad de contrastar lo indicado en otras preguntas, en las que se demuestra que tanto propietarios como procesadores de información han identificado intangibles en las organizaciones. El objetivo entonces es saber si lo que se ha identificado, también se reconoce y/o revela en los informes contables y/o financieros. Las respuestas se muestran a continuación:

¿La empresa ha registrado y/o contabilizado intangibles formados internamente?

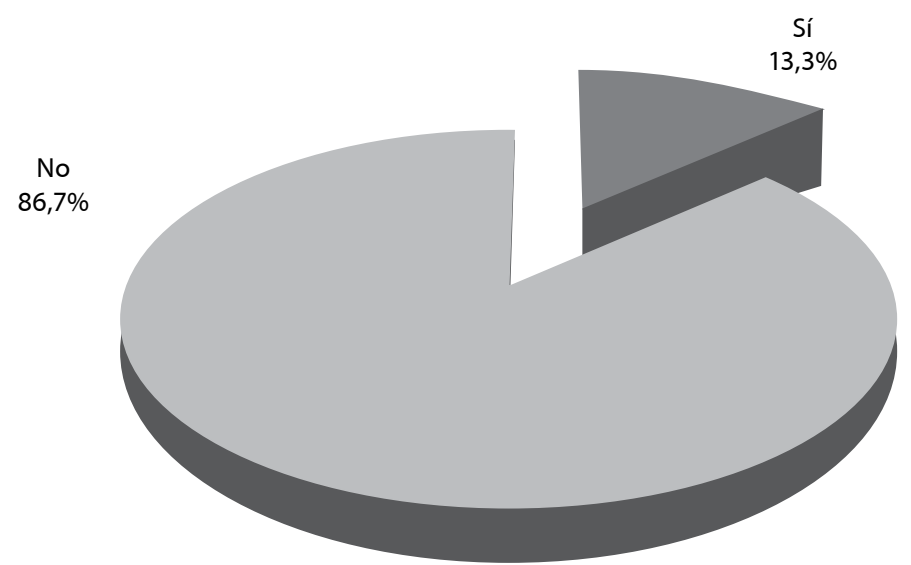

Figura 5. Reconocimiento contable de intangibles formados internamente 
Los resultados anteriores demuestran que, a pesar de que se han identificado intangibles formados internamente (good will, buen nombre, ubicación, crédito mercantil, entre otros), estos no se reconocen contablemente. Solo un $13 \%$ de los procesadores de información financiera dice haberlos reconocido contablemente, lo que indica que no hay herramientas contables lo suficientemente claras o adecuadas, que permitan cumplir los criterios de reconocimiento, para incluir este tipo de recursos en los informes contables y financieros.

\subsubsection{Existencia de métodos de medición y valoración de intangibles}

Se hace pertinente, además de saber si los intangibles son reconocidos contable y financieramente, si los propietarios de las empresas y/o los procesadores de información, utilizan métodos específicos para su medición y valoración, a efectos de ser incorporados a los informes contable-financieros. Así entonces, se les pregunta acerca de ello, y las respuestas fueron las siguientes:

Si tiene intangibles en su empresa, ¿utiliza algún método para medirlos y/o valorarlos?

$\frac{0}{2}$
$\frac{0}{0}$
$\frac{0}{4}$
$\frac{0}{0}$

100

0

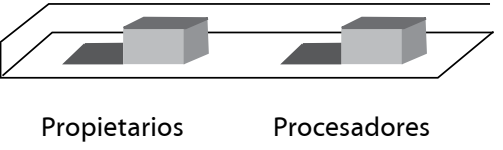

\section{Procesadores}

Figura 6. Identificación de métodos de medición y/o valoración de intangibles Fuente: elaboración propia

El resultado de esta indagación para los propietarios de las empresas, muestra que solo el 6,7\% indica que si tienen métodos de medición y valoración de intangibles, mientras que solo el 15,6\% de los procesadores de información financiera afirma contar con esos métodos. Lo anterior es evidencia del bajo conocimiento de métodos de medición y valoración de intangibles, por parte de los responsables del procesamiento de la información contable en las empresas y de los principales usuarios internos.

\subsubsection{Revelación de intangibles en la información financiera}

Además de la necesidad de reconocer, medir y valorar intangibles, es indispensable mostrar y/o revelarlos en la información contable y/o financiera. Así, se indaga tanto a propietarios de empresas como a los procesadores de información, acerca de la inclusión o revelación de los intangibles en la información que se procesa y se emite a usuarios externos. Los resultados se muestran en la figura 7: 


\section{ANÁLISIS DESCRIPTIVO Y ECONOMÉTRICO A ACTIVOS INTANGIBLES / Z. RAMÍREZ, A. GómEZ / 133}

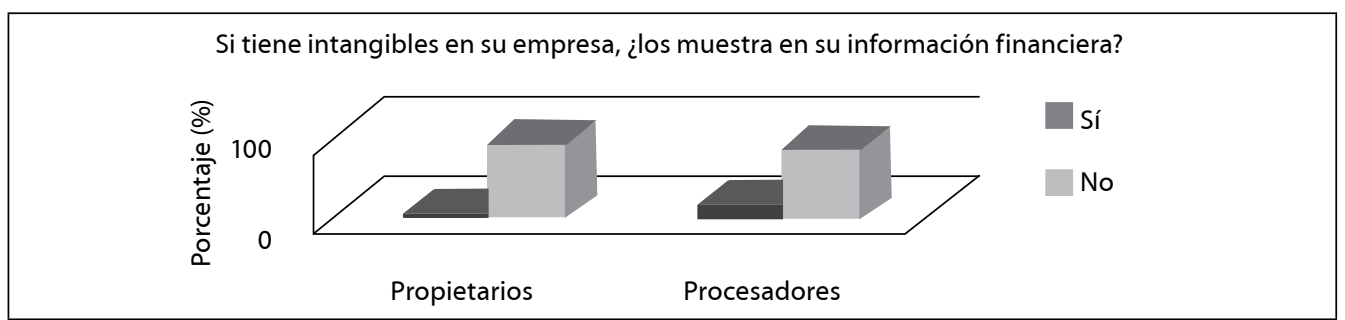

Figura 7. Revelación de intangibles en la información financiera Fuente: elaboración propia

Lo anterior podría interpretarse desde las respuestas expresadas por los propietarios de las empresas, de los cuales solo el 7\% respondió que sí revelan intangibles en la información financiera.

A manera de contraste, solo el 16\% de los procesadores de información afirma que revela o divulga intangibles en los informes contables y financieros. Esto demuestra entonces, que los intangibles siguen estando por fuera de la información contable y financiera que se procesa en las organizaciones $y$, por lo tanto, el valor que pueden generar no puede ser controlado ni interna ni externamente, lo que hace entonces que la información relativa a los recursos, activos, patrimonio y/o inversiones esté subvalorada y no intervenga en todos los procesos de análisis que podrían efectuar los usuarios externos, que solo tendrían a su disposición la información concerniente a los tangibles.

De otro lado, se indagó acerca de la afectación de la calidad de la imagen en el valor de una organización y si esto se refleja en la información contable. Estas preguntas se hicieron exclusivamente a los procesadores de información contable y las respuestas se resumen a continuación:

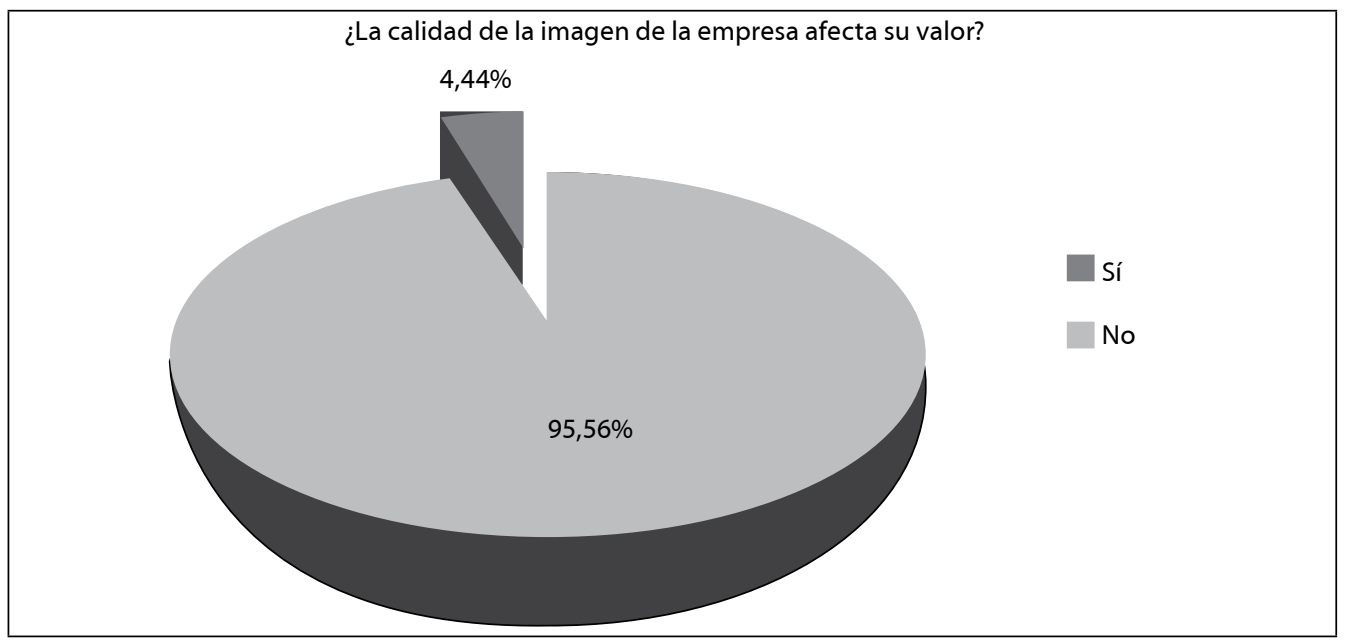

Figura 8. Relación entre la calidad de la imagen y el valor empresarial. Procesadores Fuente: elaboración propia 
Para los procesadores de información financiera (96\%), la calidad de la imagen de una organización afecta sustancialmente su valor. También fue indispensable entonces, preguntar si esa ca- lidad de la imagen empresarial que afecta de manera importante el valor de la organización, se refleja en la información contable y financiera que se procesa y se revela a usuarios externos.

¿La calidad de la imagen se refleja en la información contable y financiera procesada?

$6,67 \%$

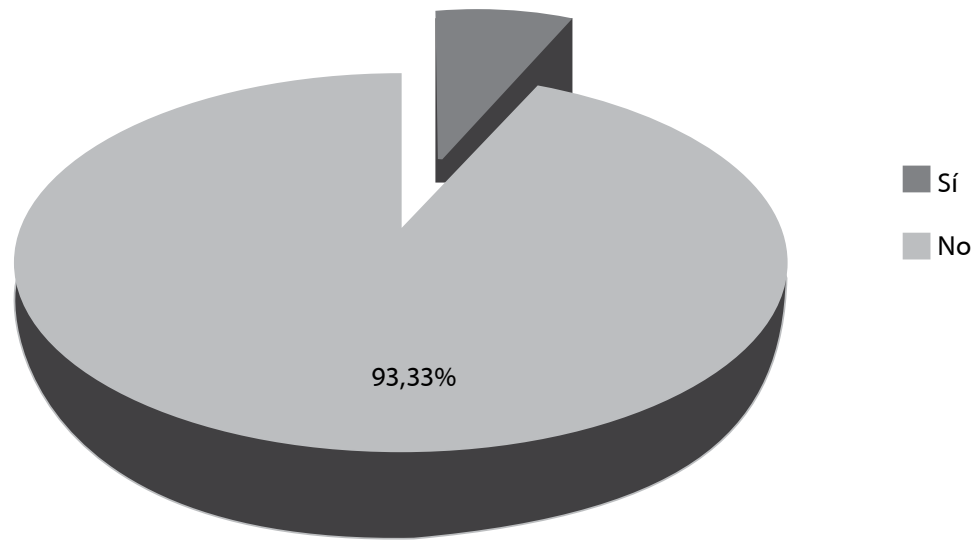

Figura 9. Revelación de la calidad de la imagen empresarial en la información contable y financiera. Procesadores Fuente: elaboración propia

Estos resultados demuestran que aunque para los procesadores de información, la calidad de la imagen de una empresa afecta sustancialmente su valor, esta no se revela en la información contable y financiera. Solo un $7 \%$ indica que sí se refleja la calidad de la imagen empresarial en los informes procesados para efectos externos.

En cuanto a la revelación, también es importante conocer el grado de importancia que los expertos-usuarios les dan a los intangibles, en la medida en que las empresas que los identifican y reconocen, los revelan en la información financiera. Así, se indagó a los usuarios de la información sobre el grado de importancia de algunos intangibles, dados en una lista, y los resultados se muestran en la tabla 8:

Los resultados muestran una clara dispersión de la percepción de los usuarios de la información, en cuanto al grado de importancia de los intangibles listados; esto denota que no hay uniformidad en esta percepción, ya que depende de la subjetividad de aquello que el usuario requiera en el momento de analizar estados financieros de una empresa en particular. Los intangibles más importantes para los usuarios de la información, cuando estos son revelados en la información contable de las empresas son el good will, las marcas de productos, las ventas y la ubicación del negocio. Así mismo, 
los menos importantes son los convenios y/o alianzas y las capacitaciones. Finalmente, los intangibles con un rango medio de importancia son el copyright, las patentes, los derechos de diseño y el estilo gerencial.

En este apartado concerniente a la revelación, también se preguntó a los usuarios de la información sobre el grado de confiabilidad que les genera una empresa que revela intangibles en su información financiera. Las respuestas de los usuarios de la información financiera demuestran que las empresas que revelan sus intangibles tienen un grado de confiabilidad alto, ya que el $70 \%$ de los expertos-usuarios encuestados superó el 60\% de confiabilidad en este aspecto específico. Esto indica que los usuarios de la información ven bien que las empresas revelen información correspondiente a sus recursos, activos y/o inversiones intangibles, porque les genera un alto grado de confiabilidad.

\begin{tabular}{|c|c|c|c|c|c|c|}
\hline \multirow{3}{*}{ Intangibles } & \multicolumn{6}{|c|}{ Usuarios } \\
\hline & \multicolumn{2}{|c|}{ Bajo (0\% a 20\%) } & \multicolumn{2}{|c|}{ Medio (21\% a $60 \%)$} & \multicolumn{2}{|c|}{ Alto (61\% a $100 \%)$} \\
\hline & FA & FR & FA & FR & FA & FR \\
\hline Marcas corporativas & 16 & $32,0 \%$ & 9 & $18,0 \%$ & 25 & $50,0 \%$ \\
\hline Marcas de productos & 10 & $20,0 \%$ & 4 & $8,0 \%$ & 36 & $72,0 \%$ \\
\hline Derechos de diseño & 18 & $36,0 \%$ & 18 & $36,0 \%$ & 14 & $28,0 \%$ \\
\hline Copyright & 19 & $38,0 \%$ & 22 & $44,0 \%$ & 9 & $18,0 \%$ \\
\hline Patentes & 16 & $32,0 \%$ & 18 & $36,0 \%$ & 16 & $32,0 \%$ \\
\hline Fidelidad de los clientes & 14 & $28,0 \%$ & 10 & $20,0 \%$ & 26 & $52,0 \%$ \\
\hline Good will & 2 & $4,0 \%$ & 3 & $6,0 \%$ & 45 & $90,0 \%$ \\
\hline Capacitación & 26 & $52,0 \%$ & 15 & $30,0 \%$ & 9 & $18,0 \%$ \\
\hline $\begin{array}{l}\text { Publicidad, promoción y } \\
\text { propaganda }\end{array}$ & 22 & $44,0 \%$ & 14 & $28,0 \%$ & 14 & $28,0 \%$ \\
\hline Convenios/alianzas & 27 & $54,0 \%$ & 15 & $30,0 \%$ & 8 & $16,0 \%$ \\
\hline Estilo gerencial & 16 & $32,0 \%$ & 19 & $38,0 \%$ & 15 & $30,0 \%$ \\
\hline Ubicación del negocio & 13 & $26,0 \%$ & 10 & $20,0 \%$ & 27 & $54,0 \%$ \\
\hline Ventas & 15 & $30,0 \%$ & 4 & $8,0 \%$ & 31 & $62,0 \%$ \\
\hline
\end{tabular}

Tabla 8. Grado de importancia de los intangibles Fuente: elaboración propia

FA. Frecuencia absoluta

FR. Frecuencia relativa 


\subsubsection{Importancia de los intangibles}

Para indagar acerca de la importancia de los intangibles, para propietarios de empresas, procesadores y usuarios de información, se realizaron algunas preguntas sobre los crite- rios económico-financieros y de mercado a tener en cuenta en la venta de los negocios, la relevancia de la imagen empresarial, y el éxito y confiabilidad de una empresa al visualizar intangibles.

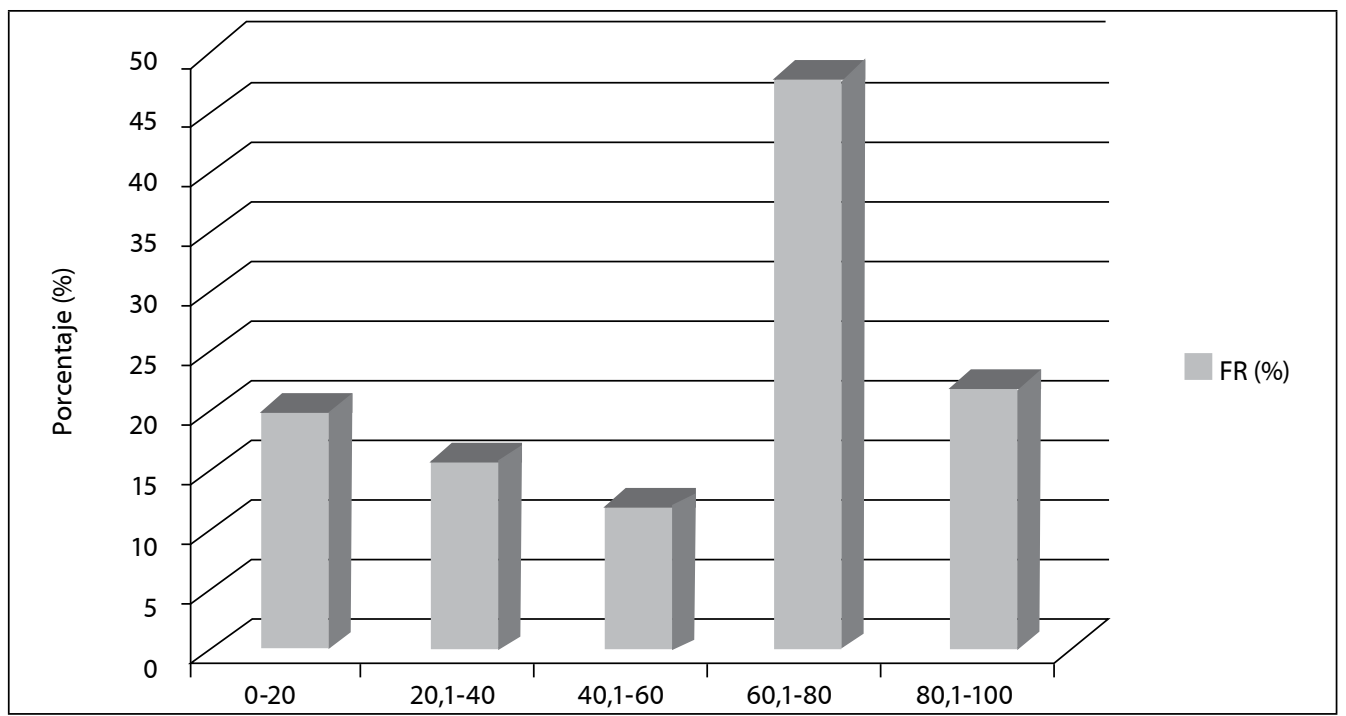

Figura 10. Grado de confiabilidad generada a los usuarios, por una empresa que revela intangibles en la información financiera Fuente: elaboración propia

FR. Frecuencia relativa

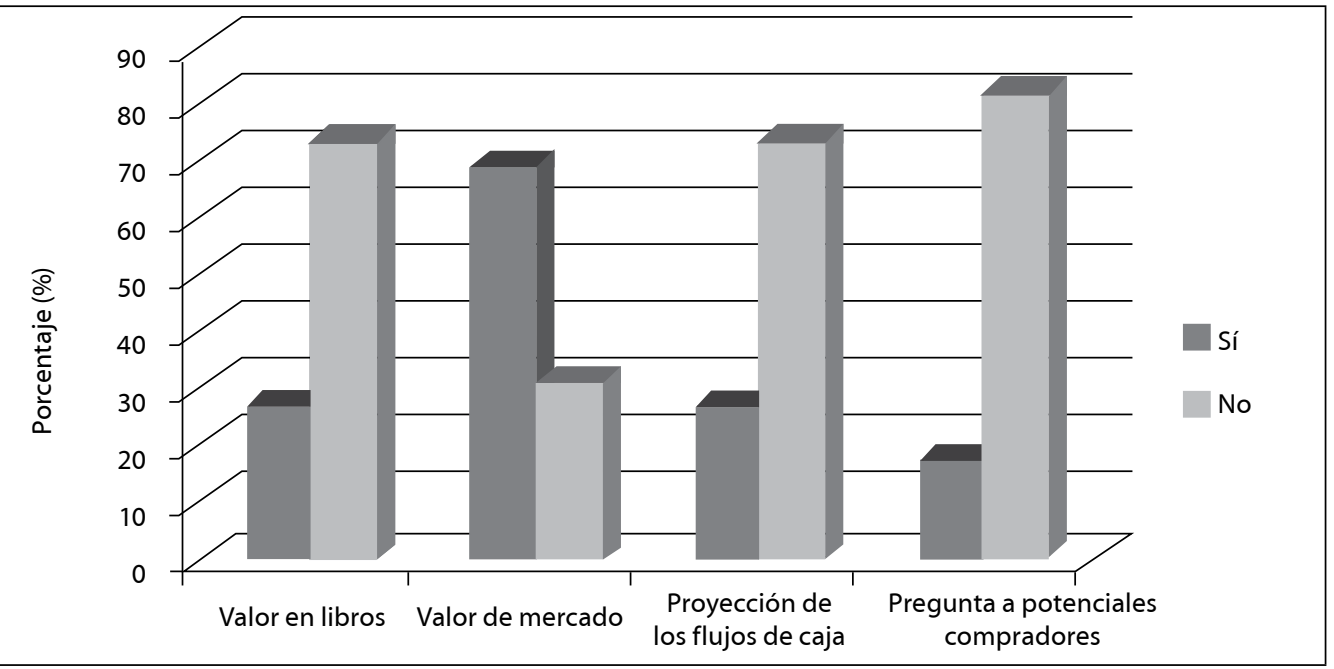

Figura 11. Factores a tener en cuenta por los propietarios, en el momento de vender la empresa 


\section{ANÁLISIS DESCRIPTIVO Y ECONOMÉTRICO A ACTIVOS INTANGIBLES / Z. RAMÍREZ, A. GóMEZ / 137}

Lo anterior demuestra que el valor de mercado es el factor más importante que el $69 \%$ de los propietarios de empresas encuestados tendría en cuenta, lo que evidencia que las otras tres alternativas no son tan importantes, incluido el valor en libros, que solo el $27 \%$ de los propietarios tendría en cuenta.
$\mathrm{Al}$ igual que se pregunta a los propietarios de las empresas, también se requiere indagar a los procesadores de información, sobre cuál criterio de los listados sería el más conveniente a tener en cuenta en el momento de venta de una empresa. Los resultados, para contrastarlos con los anteriores, se muestran en la figura 12:

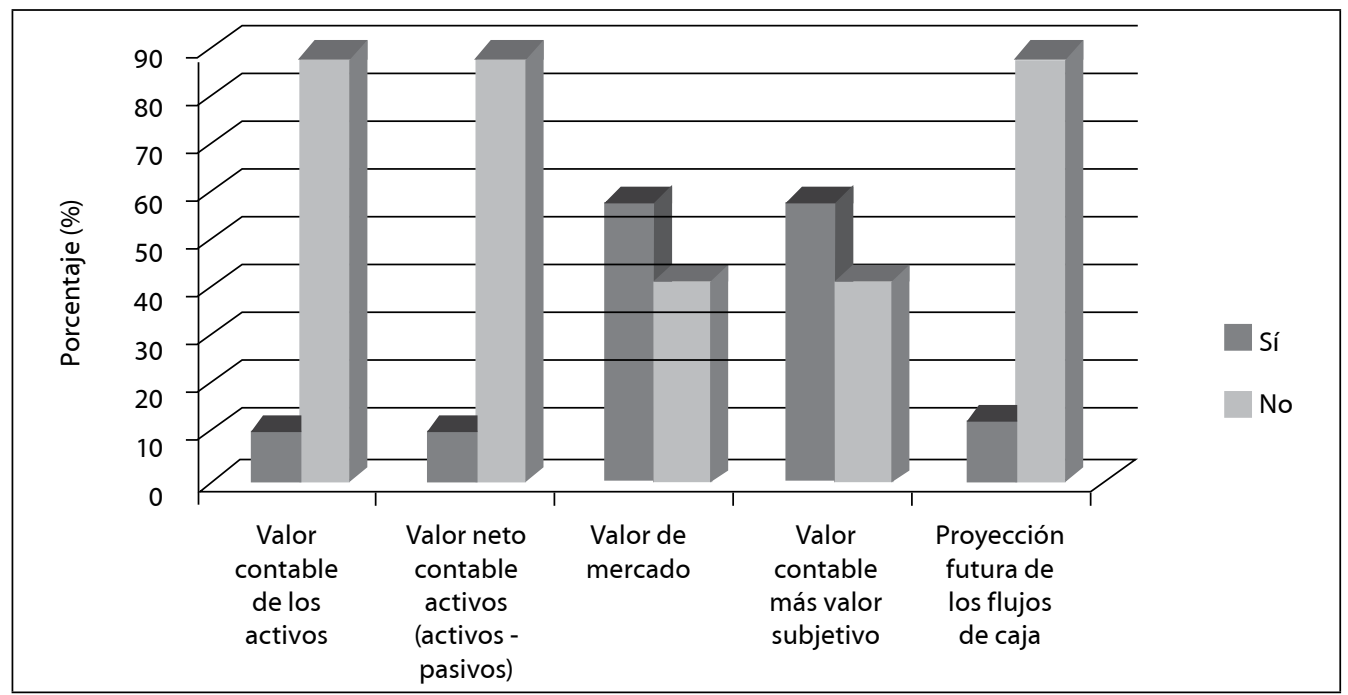

Figura 12. Factores a tener en cuenta por parte de los procesadores de información, como recomendación en el momento de venta de una empresa

Fuente: elaboración propia

Lo que se muestra en la figura 12 demuestra que el 58\% de los procesadores de información recomienda tener en cuenta, tanto el valor de mercado como el valor contable más un valor subjetivo, en el momento de vender una empresa, lo que deja muy por debajo el criterio del valor neto contable y proyección de flujos de caja. Esto se puede interpretar como una muestra de que la información contable y financiera es incompleta y no muestra o revela algunos elementos claves de una organización, que deben ser tenidos en cuenta en el momento de realizar una negociación de compra o venta.
Para contrastar los criterios que se deberían tener en cuenta al momento de vender una empresa, cuando propietarios y procesadores de información prefieren el criterio de valor de mercado, también tiene que ser relevante el concepto de los usuarios de la información, que se convierten en un componente importante del mercado, que ofrece ese valor subjetivo, durante la negociación. Esto pretende demostrar que se hace necesario el reconocimiento y revelación de intangibles en la información financiera, para reducir la brecha entre el valor en libros y el valor de mercado 
de las empresas, como una forma de brindar información de calidad a los usuarios. Se indagó a los usuarios sobre los criterios que se tienen en cuenta para considerar una empresa como exitosa y, por lo tanto, atractiva para inversionistas.

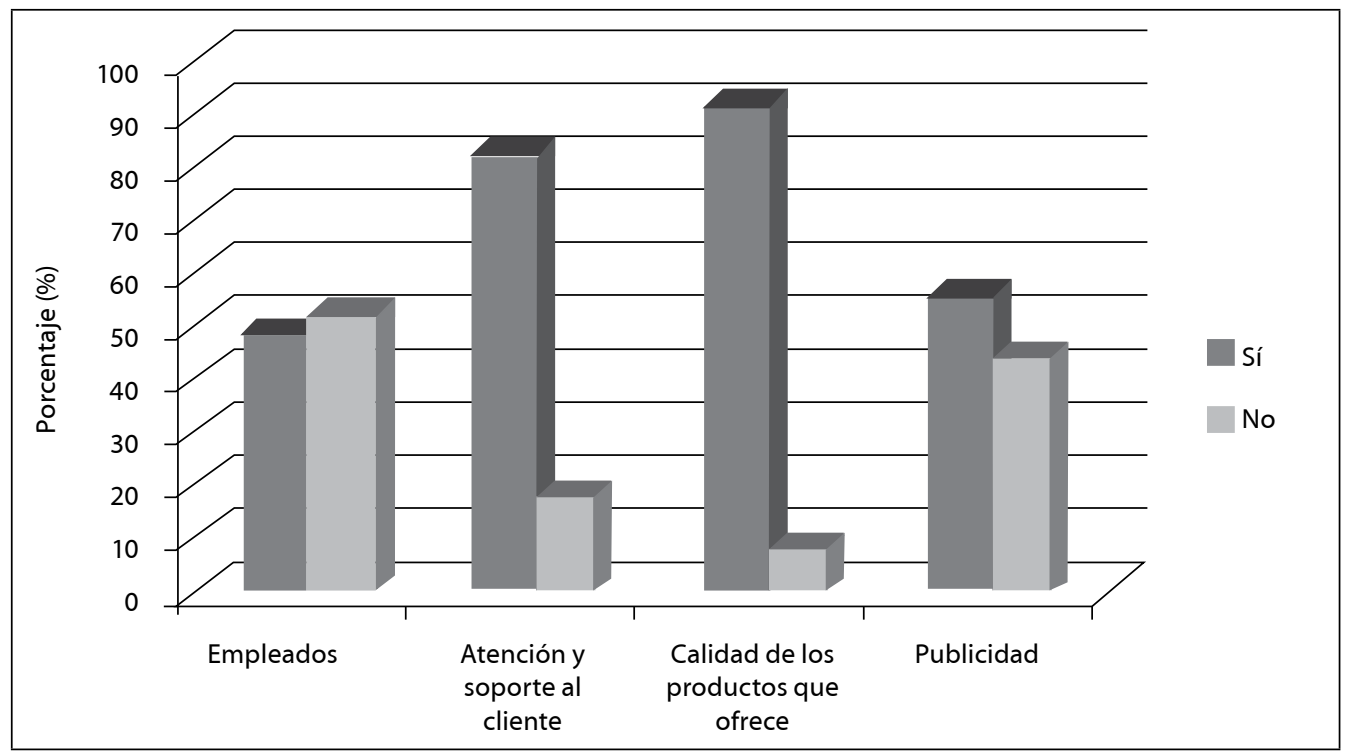

Figura 13. Factores claves de éxito empresarial, para los usuarios de la información Fuente: elaboración propia

El 92\% de los usuarios de la información indica que la calidad de los productos que ofrece es el inductor de éxito más importante en una organización, seguido de la atención y el soporte al cliente. Estos resultados muestran que para los usuarios de la información, el concepto de calidad es una condición importante y que se tiene en cuenta para considerar una empresa como exitosa, al igual que la forma en que deleita a los clientes, con un buen servicio y atención.

Además, los usuarios de la información consideran otros factores claves de éxito para las empresas, como la buena administración, la cantidad de inventario, la función social, la garantía y confiabilidad brindada a los clientes, la confianza, la organización, el nivel de ventas, la planta física, el posicionamiento, la ubicación, y la ubicación y posicionamiento en el mercado.

\section{Análisis de resultados. Metodología de estudio de casos}

\subsection{Introducción metodológica e identificación de la muestra}

Para el trabajo de campo se ha contado con cuatro empresas, dos de ellas pertenecientes al sector de los servicios con la actividad económica de "desarrollo e implementación de software empresarial", una de ellas perteneciente al sector comercial con actividad económica "ven- 
ta de materiales para el sector de la construcción" y por último, la empresa del sector industrial con actividad económica "confección y distribución mayorista de implementos deportivos".

\subsection{Resultados de la encuesta}

Para efectos del estudio de casos, la encuesta se dividió estratégicamente en cinco (5) apartados: datos referentes a la actividad económica, datos relacionados con los intangibles, con el capital humano, con el capital relacional y los datos relacionados con el capital estructural. Así, los resultados obtenidos, de manera consolidada para las cuatro empresas objeto de estudio, fueron:

\subsubsection{Datos relacionados con la actividad económica}

1. Actividad económica que desarrollan. De las cuatro empresas objeto de estudio, dos (2) son empresas de servicios (software), una (1) es comercial y una (1) es industrial.

2. Productos y/o servicios que comercializan. Las empresas de servicios se dedican a la creación de software empresarial, la empresa comercial se dedica a la compra y venta de materiales para la construcción y la empresa industrial a la fabricación, confección y distribución de implementos deportivos.

3. Creación o comercialización de nuevos productos. Para las cuatro empresas, independientemente de la actividad que desarrollen, cada una de ellas está diseñando estrategias para competir en el futuro, creando y/o comercializando nuevos productos, que no fueron revelados.

4. Existencia de sucursales. Solo una de las empresas encuestadas (de servicios) tiene sucursales en el exterior. Las otras tres empresas no tienen sucursales.

\subsubsection{Datos relacionados con los intangibles}

1. Conocimiento del término intangible. Hay pleno conocimiento del término en las cuatro empresas encuestadas.

2. Existencia de intangibles en la organización. Todas las empresas encuestadas indican tener intangibles en su organización.

3. Valoración de intangibles en la organización. De las cuatro empresas encuestadas para este estudio de casos, solo una (1) empresa indicó que les asigna un valor a los intangibles que se tienen, utilizando un método empírico de medición y valoración, únicamente por requisitos de clientes y proveedores externos. Las tres empresas restantes indican que no les otorgan ningún valor a los intangibles que tienen en sus organizaciones.

4. Categorías de intangibles que manejan las organizaciones. Los intangibles que tienen un mayor grado de identificación en las empresas son la publicidad, propaganda y promoción, y el good will; seguidos de marcas corporativas, marcas de productos, y convenios y alianzas. Así, a pesar de lo enunciado en el numeral 3, según el cual las empresas no valoran los intangibles, sí hay una identificación y/o reconocimiento en las organizaciones.

5. Asociación del término good will, o buen nombre del negocio. Los criterios que se asocian directamente con el término good will, son los productos, la actividad económica 
y las facilidades de pago, que son criterios tradicionales del ejercicio de una actividad empresarial. Criterios como la ubicación del negocio, los clientes, la antigüedad y la atención al cliente no se asocian directamente en todas las empresas objeto de análisis con el término good will. Además, el nombre del establecimiento solo se asocia en dos (2) empresas con el good will.

6. Asociación del término prima del negocio. Se asocia en las cuatro empresas, con los productos y la actividad económica.

7. Periodicidad de las inversiones. Según la tabulación de respuestas, se demuestra una dispersión en las condiciones de inversión, tanto en empresas de servicios, como industriales y comerciales. Se muestra que las necesidades de inversión no siempre están asociadas a las condiciones del mundo actual, que requiere inversiones importantes en capacitación, tecnología, publicidad e investigación. Además, la periodicidad indica que no se trata de prioridades periódicas, sino, al contrario, se considera que pueden ser gastos de capital o inversiones de largo plazo, que solo requieren una inversión en el período.

8. Ofrecimiento de productos y/o servicios susceptibles de ser patentados. Ninguna de las empresas objeto de análisis ofrece productos o servicios de su propiedad, que pudieran ser patentados.

\subsubsection{Datos relacionados con el capital humano}

1. Número de empleados. Las empresas de servicios cuentan con un menor número de empleados, que las empresas comercial e industrial.

2. Antigüedad de los empleados. La empresa con empleados de mayor antigüedad es la industrial, ya que más del 50\% tiene una antigüedad promedio mayor a 4 años. Lo mismo ocurre con la empresa comercial, en la que más del $50 \%$ de sus empleados lleva más de 4 años laborando allí. Para las empresas de servicios de software, como son empresas de constitución reciente, sus empleados no llevan más de 5 años en promedio con ellas.

3. Nivel de estudios de los empleados. Las empresas con empleados de mayor nivel educativo son las de servicios de software, ya que para el ofrecimiento de sus servicios requiere mayor complejidad y un proceso de formación avanzada de sus empleados, que permita desarrollar soluciones óptimas para los clientes. Al contrario, las empresas comercial e industrial, aunque tienen empleados con formación universitaria, se centran exclusivamente en aquellos que se dedican a las labores administrativas, mientras que los empleados dedicados a labores operativas tienen formación técnica o tecnológica.

4. Existencia de manuales de procesos y metodologías de sistematización. Tres (3) de las empresas encuestadas tienen sistematizado el conocimiento de los empleados, mediante manuales de procesos, que indican las formas para realizar las acciones y/o actividades, de manera detallada. Solo una (1) empresa no tiene esta sistematización. Y las metodologías indicadas para sistematizar los procesos son el libro de procedi- 
mientos, los archivos escritos (documentos en archivos y carpetas), y el módulo Competisoft.

\subsubsection{Datos relacionados con el capital relacional}

1. Bases de datos de clientes y periodicidad en la actualización. De las cuatro empresas encuestadas, tres (3) tienen bases de datos de clientes, y solo una (1) no maneja este tipo de bases de datos. De las tres empresas que tienen bases de datos de clientes, solo dos (2) de ellas las actualizan de manera periódica, y una de ellas no tiene actualizada su base de datos de clientes.

2. Bases de datos de proveedores y periodicidad en la actualización. De las cuatro empresas encuestadas, dos (2) de ellas tienen bases de datos de proveedores, y dos (2) no manejan este tipo de base de datos. De las dos empresas que tienen bases de datos de proveedores, solo una (1) de ellas la actualiza de manera periódica, y una de ellas no conserva su base de datos de proveedores actualizada.

3. Clasificación y calificación de los clientes. De la muestra encuestada, solo tres (3) empresas clasifican y califican a sus clientes. Los criterios utilizados para clasificar y calificar a los clientes tienen relación con la frecuencia de compra (periodicidad), monto de la compra (valor) y la forma de pago (cumplimiento).

4. Tipologías de los clientes. Los tipos de clientes se asocian a la naturaleza de la actividad económica que cada empresa desarrolla. Para la empresa comercial, los clientes son maestros o jefes de obra, encargados de la construcción y de las compras de materiales. Para la empresa industrial, son colegios, instituciones educativas, entidades públicas y privadas, y público en general, que requieran uniformes, dotación para trabajadores, y/o implementos deportivos. Para las empresas de servicios, son empresas que requieren un software para el desarrollo de su actividad económica, tanto para el manejo contable como administrativo.

5. Categorías de calificación para clientes. Las categorías utilizadas por las tres (3) empresas que califican a los clientes tienen relación con dos criterios fundamentales: constancia o periodicidad de compra y forma de pago o nivel de cumplimiento en el pago.

6. Ofrecimiento de servicios especializados para los clientes. Tres (3) de las empresas encuestadas ofrecen servicios de soporte y atención especializada para los clientes. Los servicios ofrecidos tienen relación con las solicitudes de los clientes, y se atienden según su fidelidad con la empresa y su capacidad de compra (adquisitiva). Las empresas que cuentan con una política de atención especializada a los clientes son las de servicios (software), ya que los clientes requieren servicios de actualización y soporte permanente.

7. Comunicación permanente con los clientes. Dos (2) de las cuatro empresas encuestadas no cuentan con ningún mecanismo de comunicación posventa con sus clientes. Las dos empresas restantes, que son las de servicios de software, tienen esencialmente comunicación telefónica con los clientes, 
para ofrecerles productos, servicios, mantenimientos y actualizaciones, entre otros.

\subsubsection{Datos relacionados con el capital estructural}

1. Aspectos organizacionales incorporados en las empresas. Según la tabulación de datos, buena parte de los aspectos organizacionales básicos está incorporada en las empresas encuestadas. En una mayor proporción, el logo y el lema, seguido de misión, visión, principios y valores corporativos; en menor proporción, se incorporan el reglamento interno de trabajo y la estructura organizacional. Las razones están asociadas al tamaño de la organización y a la composición familiar de dos de las empresas encuestadas.

2. Existencia de sistemas de información. Tres (3) de las empresas cuentan con sistemas de información asociados al control contable, como software contable, programas de Office para efectos administrativos y un software contable para nómina y presupuesto.

3. Existencia de bases de datos diferentes a clientes y proveedores. De las empresas objeto de análisis, solo dos (2) manejan bases de datos para el control de inventarios $y$ sistemas de control de ingresos y egresos. Aunque la respuesta a esta pregunta podría estar más asociada a los sistemas de información con que cuentan las empresas, el término bases de datos fue asociado también al escenario de sistemas de información, por lo que podrían combinarse las respuestas a este ítem y al anterior, lo que indica que se puede dar una desagregación del software contable mediante sistemas de inventarios, ingresos y egresos. Dos de las empresas objeto de análisis respondieron de manera negativa a la pregunta del manejo de bases de datos adicionales.

4. Existencia de manuales de procesos y procedimientos. Solo dos (2) de las empresas objeto de análisis cuentan con manuales de procesos y procedimientos, que son actualizados permanentemente, para hacer eficientes las acciones, tareas, actividades y/o procesos de la organización. Además, se indica que es una forma de tener documentado el conocimiento de los empleados y/o de las rutinas organizacionales.

\subsection{Conclusión metodología estudio de casos}

De la aplicación de este instrumento, se puede concluir que los propietarios de las empresas de la muestra escogida tienen un conocimiento amplio y suficiente de la empresa y del manejo de los intangibles en la organización. El $100 \%$ de la muestra manifiesta conocer el adjetivo intangibles y logra identificarlos dentro de la organización, aunque no tiene métodos de medición, valoración y no los revela en la información financiera. Estas empresas tienen intangibles como las bases de datos de clientes, proveedores y otras; consideran a los clientes como un intangible importante, aunque en muchas ocasiones no tienen servicios que mejoren la atención y logren fidelizarlos. Con la revisión documental, se confirma que, aunque son muchos los intangibles que logran identificar dentro de la organización, solo unos pocos se muestran en la información contable. Los únicos intangibles que se muestran son los per- 
tenecientes al grupo 16 (good will estimado) del Plan Único de Cuentas, y de manera estimada, sin ningún parámetro ni criterio de medición y/o valoración.

Así, a partir de la utilización de herramientas de investigación cualitativa (metodología Delphi y estudio de casos), se deduce la imperiosa necesidad de contar con un modelo que ayude a las organizaciones a sistematizar el conocimiento relativo a sus intangibles, mediante la identificación, reconocimiento, medición, valoración y revelación en la información contable y financiera.

\section{Modelo econométrico}

Para complementar y ahondar el análisis descriptivo anterior, se efectúa un análisis econométrico, a partir de los datos obtenidos por los procesadores de información contable y financiera. Se utilizan las respuestas dadas por ellos, pues son los que tienen la formación en el campo contable (mayor grado de conocimiento), los responsables del procesamiento de la información (mayores posibilidades de identificación, reconocimiento y revelación) en las organizaciones; y los que deben enlazar el grado de conocimiento, con la identificación, reconocimiento, medición, valoración y revelación de intangibles.

El objetivo de este análisis es mostrar la posibilidad de que las empresas encuestadas revelen o divulguen los intangibles en la información financiera, si conocen el adjetivo intangible, identifican y reconocen intangibles en la empresa, y cuentan con métodos de medición y valoración para hacerlo. Este análisis economé- trico pertenece a la familia de los modelos de variable dependiente limitada, más exactamente a los modelos logísticos o Logit. ${ }^{6}$ Por tanto, la pretensión no es otra que mostrar un conjunto de probabilidades explicadas por variables ${ }^{7}$ que muestren la probabilidad de encontrar procesadores de información que aun teniendo conocimiento de causa frente a la presencia de intangibles en su empresa no los revelan en los informes contables.

Estos modelos profundizan lo hallado anteriormente con los datos, pues permiten simular diversos escenarios en los cuales se muestra que dependiendo del grado de conocimiento sobre intangibles, de su identificación y reconocimiento, y los métodos de medición y valoración, hay un cambio en las probabilidades de que las empresas revelen sus intangibles en la información contable y financiera.

\subsection{Modelo Logit ${ }^{8}$}

Se implementó una modelación logística para capturar la probabilidad de que una empresa revele o muestre los intangibles en la información financiera (Rev), si en primer lugar conoce y clasifica el término intangible (Cono); en segundo lugar, si identifica y reconoce los intangibles (Rec) y finalmente, si la empresa tiene

6 No se utilizan los modelos MPL por sus problemas conocidos (probabilidades mayores a uno e inferiores a cero, o cambios de probabilidad siempre iguales), tampoco se consideraron los modelos Probit pues su probabilidad se acerca a cero o a uno a una tasa más rápida que los modelos Logit. Adicionalmente, en términos relativos, su complejidad matemática es más alta que en los Logit.

7 Conocimiento del término intangible, identificación y reconocimiento de intangibles, medición y valoración de intangibles, revelación contable.

8 Para una explicación de estos modelos, se puede consultar William H. Greene (1998, cap. 19, p. 749). 
métodos de medición y valoración de intangibles (Med). Como la matriz de correlaciones simples evidencia que las variables Cono y Med están relacionadas y, por tanto, se presentan problemas de multicolinealidad, se implementa la técnica de los componentes principales, la cual es una combinación lineal entre variables para capturar en una sola todas las explicativas del modelo.

En términos generales, el método intenta "extraer" la información relevante de un conjunto de datos al eliminar de ellos la información redundante, o poco relevante. En términos más precisos, si $\mathbf{X}$ es la matriz que relaciona los valores que asumen las variables bajo análisis en cada período, se tiene que:

$X=\left[\begin{array}{cccc}x_{11} & x_{12} & \ldots & x_{1 p} \\ x_{21} & x_{22} & \ldots & x_{2 p} \\ \vdots & \vdots & \vdots & \vdots \\ x_{n 1} & x_{n 2} & \ldots & x_{T p}\end{array}\right]_{T x p}$

Donde

$\mathbf{X} \in \mathrm{R}^{\mathrm{p}}, p$ es la $p$-ésima variable $n$ es la $n$-ésima empresa bajo análisis

El objetivo a partir de este punto entonces, es lograr transformar la matriz $\boldsymbol{X}$ en otra que se pueda proyectar en $k$, donde $k<p$, es decir, reducir la dimensionalidad de $\mathbf{X}$ desde $p$ hasta $k$ y que, por tanto, las $k-p$ variables fuesen irrelevantes. Sea $\mathbf{F}$ la nueva matriz proveniente de la transformación de la matriz $\mathbf{X}$, los coeficientes de $\mathbf{F}$ deben ser ortogonales, es decir, no deben tener ningún tipo de relación lineal, por tanto, no debe existir multicolinealidad. Así, F se puede expresar como:

$F=\left[\begin{array}{cccc}F_{11} & F_{12} & \ldots & F_{1 p} \\ F_{21} & F_{22} & \ldots & F_{2 p} \\ \vdots & \vdots & \vdots & \vdots \\ F_{n 1} & F_{n 2} & \ldots & F_{T p}\end{array}\right]_{T x p}$

La técnica de los componentes principales permite reducir la matriz $\mathbf{F}$ hasta un vector columna con la siguiente estructura:

$f=\left[\begin{array}{l}f_{1} \\ f_{2} \\ f_{3} \\ f_{p}\end{array}\right]_{p x 1}$

Para obtener el vector $f$, se debe tomar la matriz de coeficientes de información de las variables relevantes y descomponerlos en sus vectores de la siguiente forma:

$A=\left[\begin{array}{cccc}a_{11} & a_{12} & \ldots & a_{1 p} \\ a_{21} & a_{22} & \ldots & a_{2 p} \\ \vdots & \vdots & \vdots & \vdots \\ a_{p 1} & a_{p 2} & \ldots & a_{p p}\end{array}\right]_{p x p}$

$a_{1}=\left[\begin{array}{l}a_{11} \\ a_{12} \\ a_{13} \\ f_{1 p}\end{array}\right]_{1 x p} a_{2}=\left[\begin{array}{l}a_{21} \\ a_{22} \\ a_{23} \\ f_{2 p}\end{array}\right]_{2 x p} a_{i}=\left[\begin{array}{c}a_{i 1} \\ a_{i 2} \\ a_{i 3} \\ f_{i p}\end{array}\right]_{i x p}$ 


\section{ANÁLISIS DESCRIPTIVO Y ECONOMÉTRICO A ACTIVOS INTANGIBLES / Z. RAMÍREZ, A. GóMEZ / 145}

En notación matricial, la matriz F se puede expresar como:

$$
F_{p x 1}=A_{p x p} X_{p x 1}
$$

Y en notación vectorial, cada componente principal se puede expresar como:

$$
\begin{aligned}
& F_{1}=a_{1}^{T} X_{p x 1} \\
& F_{2}=a_{2}^{T} X_{p x 1} \\
& F_{k}=a_{p}^{T} X_{p x 1}
\end{aligned}
$$

El vector columna formado por estos valores propios en cada caso, se constituye en la va-

Logistic regression

Log pseudolikelihood $=-5.8390844$

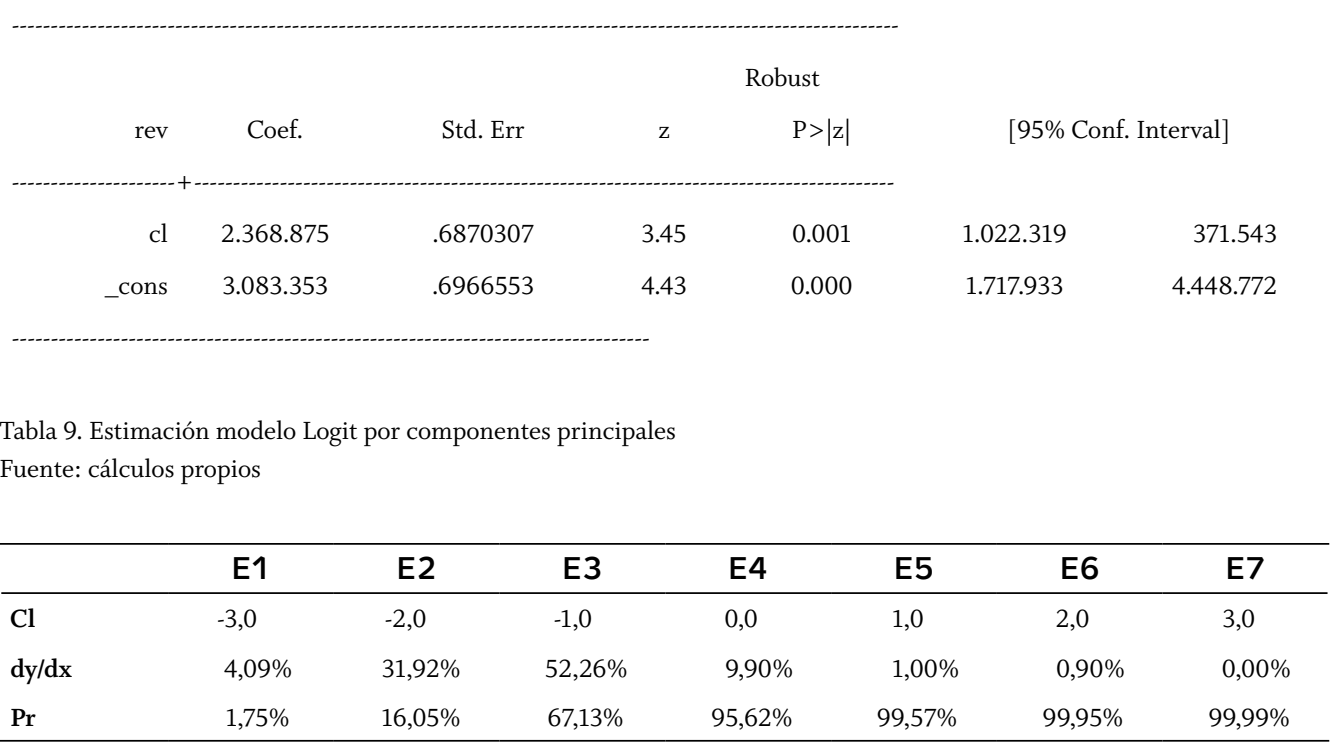

riable que se busca. Por tanto, el modelo es el siguiente:

$$
\begin{aligned}
& \operatorname{Rev}_{i}=\mathrm{b}_{1}+\mathrm{b}_{2} \mathrm{Cl}_{i}+U_{i} \\
& \mathrm{i}=1, \ldots 45
\end{aligned}
$$

Donde

Rev es definida como antes y la variable $\mathrm{Cl}$ es la combinación lineal de las variables Cono, Rec y Med. Finalmente, la variable Ui son los errores estocásticos, pues recoge todas las variables que afectan a la variable dependiente pero que no han sido consideradas de forma explícita en el modelo, que siguen una distribución logística. Los resultados que fueron obtenidos bajo máxima verosimilitud fueron los siguientes:

$$
\begin{array}{ll}
\text { Number of obs } & =45 \\
\text { Wald chi2 }(1) & =11.89 \\
\text { Prob }>\text { chi } 2 & =0.0006
\end{array}
$$

Pseudo R2 $=0.6998$ 
Donde

E1: Escenario 1

E2: Escenario 2

E3: Escenario 3

E4: Escenario 4

E5: Escenario 5

E6: Escenario 6

E7: Escenario 7

Pr: probabilidad

Efecto Marginal: dy/dx

Los resultados relacionados evidencian que estadísticamente hablando, el modelo presenta un buen ajuste, toda vez que el pseudo- $R^{2}$ es igual a 0,69; lo que traduce que la capacidad explicativa del modelo es considerablemente alta. De otro lado, tanto la constante como la variable tienen una significancia estadística muy alta, ya que el p-valor es casi cero. El resultado del coeficiente que acompaña a $C l$, que en este caso es $(2,36)$, solo sirve para validar su signo, por tanto, como es positivo muestra que existe una relación directa entre la probabilidad de que una empresa revele sus intangibles, basado en que conoce el término intangible, los identifica y reconoce y tiene métodos para su medición y valoración.

La tabla siguiente relaciona los efectos marginales de la variable $\mathrm{Cl}$ para diversos escenarios y las probabilidades asociadas a ellos. ${ }^{9}$ En general, se puede observar que la probabilidad de revelar los intangibles es creciente en

9 El número de escenarios puede ser infinito ya que depende del valor que asuma en los números reales la variable $\mathrm{Cl}$, la cual por estar expresada como una desviación estándar se encuentra en el intervalo entre $-3 y+3$. Aquí se eligen solo siete valores enteros (o sea, siete escenarios) en ese intervalo. la medida en que la variable $\mathrm{Cl}$ asume valores cada vez más altos en su desviación estándar. En este orden de ideas, el escenario 1 muestra que para valores bajos de $\mathrm{Cl}$ (es decir, si la empresa conoce muy poco el adjetivo intangible), la probabilidad de que los revele en su información financiera es igual al 1,75\%, pero ya el escenario 3 muestra que si el valor de $\mathrm{Cl}=-1$, es decir, si conoce el término medianamente bien, la probabilidad de que los revele en sus estados contables y financieros (67,7\%) es muy elevada. Un escenario extremo - como el número 7evidencia una probabilidad casi del 100\%.

Los efectos marginales (dy/dx) también muestran este comportamiento. Entendidos como las modificaciones en la probabilidad de éxito cuando se modifica la variable explicativa, sus valores concentran la mayor variabilidad en los escenarios $2(0,31)$ y $3(0,52)$, por lo que las empresas requieren conocer el término o adjetivo intangible de manera amplia, identificar y reconocer los intangibles en la organización y/o contar con métodos de medición y valoración sofisticados, pues la modificación de la probabilidad a favor de su revelación y/o divulgación es considerable.

\section{Conclusiones}

Las dinámicas propias de la sociedad del conocimiento, como un mundo donde transitan elementos tangibles e intangibles, han demostrado la gran importancia y relevancia de estos últimos, como generadores y/o destructores de valor para las organizaciones $y$, por lo tanto, se hace apremiante que procesadores de información contable y financiera sean agentes prin- 
cipales en la conceptualización, identificación y revelación de estos intangibles, para que los usuarios perciban una mayor confiabilidad y calidad de la información.

Investigar la temática de intangibles es un reto de complejidad, ya que el abordaje metodológico puede ser desestimulante en el proceso. Así que esta ha sido una propuesta atrevida que ha mezclado metodologías cualitativas (Delphi, estudio de casos) y cuantitativas (econometría), para llegar a mostrar las ventajas alrededor de ellas. El uso de metodologías cualitativas permite un mayor acercamiento con los agentes, teniendo de por medio el objeto de estudio, lo que ayuda a que el proceso investigativo sea interactivo y enriquecido por las personas.

Como conclusión importante, a partir de los cuestionarios y entrevistas aplicadas en las metodologías cualitativas, se encuentra que, a pesar de un gran conocimiento percibido por propietarios, procesadores y usuarios de información financiera, el tránsito hacia la identificación, reconocimiento, medición, valoración y revelación de intangibles aún es pobre y desalentador; lo que debe ser un reto para investigadores en el camino de proponer modelos alternativos que permitan la revelación de intangibles, en términos de fiabilidad, comprensibilidad y razonabilidad. Así, con todo el trabajo de campo como evidencia empírica, se deduce la imperiosa necesidad de contar con modelos que ayuden a las organizaciones a sistematizar (reconocer, medir, valorar y revelar) el conocimiento relativo a los intangibles, ya que se reconoce una gran dispersión conceptual, que no favorece las posibilidades de revelación en la información contable y financiera.
En el camino de construcción de modelos econométricos se aborda un primer escenario, en el cual la probabilidad de revelación de intangibles en los estados financieros de las empresas es creciente, si se tienen métodos de medición y valoración, y decreciente, si solo se tiene conocimiento del adjetivo intangible. Es decir, si las empresas tienen formas de medir y valorar los intangibles es porque ya tienen un bagaje conceptual, pero si carecen de elementos conceptuales para su abordaje, tampoco tendrán formas de medir, valorar y mucho menos revelarlos en la información contable. En el medio de estos extremos están agentes que tienen conocimiento del adjetivo intangible y los identifican y reconocen en las organizaciones, pero no se miden ni se valoran y, por tanto, no se divulgan en la información financiera. El escenario de los componentes principales es concordante con lo anterior, pues evidencia que conocer el término o adjetivo intangible no es suficiente, sino que se hace necesario identificarlos, reconocerlos y tener métodos de medición y valoración para revelarlos en la información contable y financiera. La contribución de este estudio es hacer conciencia de la brecha existente entre el conocimiento de los intangibles y la revelación en la información contable y financiera; esta distancia solo se podrá reducir, en la medida en que se propongan modelos para medir y valorar los intangibles, con herramientas comprensibles, fiables y concordantes con principios de razonabilidad contable y sobre todo de revelación plena.

Tener la posibilidad de procesar respuestas relativas a los intangibles, por parte de los expertos vinculados a la información contable y 
financiera de las organizaciones (propietarios, procesadores y usuarios de información), y además contrastarlas con la evidencia documental de las empresas industriales, comerciales y de servicios, ratifica cualitativa y conceptualmente la importancia del abordaje investigativo en materia de intangibles desde las disciplinas contable, económica y administrativa, que originalmente han dado primacía al abordaje de lo "material" o "tangible", mediante su reconocimiento y revelación. Se demuestra empíricamente la amplia brecha existente entre lo que se conoce y reconoce en materia de intangibles y lo que realmente se divulga en la información contable y financiera, lo que debe alentar a ampliar los esfuerzos en formación, regulación y difusión metodológica en torno a la temática de los intangibles, desde una perspectiva multidisciplinar.

\section{Referencias}

Abdel-Khalik, A. Rashad (1975). Advertising Effectiveness and Accounting Policy. The Accounting Review, 50 (4), 657-670.

Berardi-Bifo, Franco (2003). La fábrica de la infelicidad. Nuevas formas de trabajo y movimiento global. Barcelona: Editorial Traficantes de Sueños.

Brennan, Beverley A. (1992). Mind over Matter: How Current Accounting Practice Hobble Innovative Companies. CA Magazine, 125 (6), 20-24.

Brooking, Annie (1997). El capital intelectual: el principal activo de las empresas del tercer milenio. Barcelona: Paidós.

Bueno-Campos, Eduardo (1998). El capital intangible como clave estratégica en la competencia actual. Boletín de Estudios Económicos, 53 (164), 207-229.

Cañibano-Calvo, Leandro \& Sánchez-Muñoz, María Paloma (coords.) (2004). Lecturas sobre intangibles $y$ capital intelectual = readings on intangibles and intellectual capital. Madrid: Asociación Española de Contabilidad y Administración de Empresas, AECA.

Chaminade, Cristina; Sánchez-Ortín, Pedro Luis \& Escobar, Carmen Gloria (1999). En busca de una teoría sobre la medición y gestión de los intangibles en la empresa: una aproximación metodológica. Ekonomiaz: Revista Vasca de Economía, 45, 188-213. Disponible en: http://dialnet.unirioja.es/servlet/ articulo? codigo $=265867$

Chauvin, Keith W. \& Hirschey, Mark (1993). Advertising, R\&D Expenditures and the Market Value of the Firm. Financial Management, 22 (4), 128-140.

Edvinsson, Leif \& Malone, Michael (1997). El capital intelectual. Barcelona: Grupo Editorial Norma.

Edvinsson, Leif \& Malone, Michael (1999). El capital intelectual: cómo identificar y calcular el valor de los recursos intangibles de la empresa. Barcelona: Ediciones Gestión.

García-Ayuso Covarsí, Manuel; Sánchez Muñoz, María Paloma \& Cañibano-Calvo, Leandro (2004). Accounting for Intangibles: A Literature Review. En Leandro CañibanoCalvo \& María Paloma Sánchez-Muñoz, (coords.). Lecturas sobre intangibles y capital intelectual $=$ Readings on Intangibles and Intellectual Capital, 41-79. Madrid: Asociación Española de Contabilidad y Administración de Empresas, AECA. 
Greene, William H. (1998). Análisis econométrico. Madrid: Pearson Educación.

Hansson, Bo (1997). Personnel Investments and Abnormal Return: Knowledge-Based Firms and Human Resource Accounting. Journal Human Resource Costing Accounting, 2 (2), 9-29. doi:10.1108/eb029037

Kaplan, Robert \& Norton, David (1992). The Balanced Scorecard: Measure that Drive Performance. Harvard Business, 70 (1), 7179. Disponible en: https://hbr.org/2005/07/ the-balanced-scorecard-measures-thatdrive-performance, http://www.csee.umbc. edu/ sweet/Ph.D/papers/BSC/BSC\%20 -\%20Measures\%20that\%20drive\%20 performance.pdf

Kaplan, Robert \& Norton, David (1996). Using the Balanced Scorecard as a Strategic Management System. Harvard Business, 74 (1), 75-85. Disponible en: https://hbr. org/2007/07/using-the-balanced-scorecardas-a-strategic-management-system

Lev, Baruch (2003). Intangibles: medición, gestión e información. Barcelona: Ediciones Deusto.

Nevado-Peña, Domingo \& López-Ruiz, Víctor Raúl (2004). Una herramienta de gestión de intangibles ocultos mediante técnicas econométricas. Método y Aplicación. Revista de Contabilidad y Dirección, 1, 163-182. Disponible en: http://www.accid.org/revista/documents/ intangibles_castellano_163-182.pdf, http://mxavasp2.accid.org/revista/ documents/3.Herramienta_gestion_ de_intangibles_ocultos_mediante_
tecnicas_econometricas._D.Nevado_y_V. Raul_Lopez.pdf

Nonaka, Ikujiro \& Takeuchi, Hirotaka (1995). The Knowledge-Creating Company. How Japanese Companies Create the Dynamics of Innovation. New York: Oxford University Press, OUP. Roos, Johan; Edvinsson, Leif \& Roos, Göran (1998). Intellectual Capital: Navigating in the New Business Landscape. New York: New York University Press, NYU Press.

Roos, Johan \& Roos, Göran (1997). Valuing Intellectual Capital: The Next Generation. Financial Time, Mastering Management, May.

Roos, Johan; Roos, Göran; Dragonetti, Nicola C. \& Edvinsson, Leif (2001). Capital intelectual. El valor intangible de la empresa. Barcelona: Ediciones Paidós Ibérica.

Salinas, Gabriela (2007). Valoración de marcas. Revisión de enfoques, metodologías y proveedores. Barcelona: Ediciones Deusto.

Sougiannis, Theodore (1994). The Accounting Based Valuation of Corporate R\&D. The Accounting Review, 69 (1), 44-68.

Sveiby, Karl-Erik (1996). The Intangible Assets Monitor. Journal of Human Resource Costing and Accounting, 2 (1), 73-97.

Tejedor, Beatriz \& Aguirre, Ane (1998). Proyecto Logos: investigación relativa a la capacidad de aprender de las empresas españolas. Boletín de Estudios Económicos, 53 (164), 231-249.

- Fecha de recepción: 31 de agosto de 2014

- Fecha de aceptación: 30 de abril de 2015

- Disponible en línea: 30 de abril de 2015 
150 / VOL. 16 / NO. 40 / ENERO-ABRIL 2015

\section{Para citar este artículo}

Ramírez-Gutiérrez, Zoraida \& Gómez-Sánchez, Andrés Mauricio (2015). Grado de conocimiento del adjetivo "intangibles", y su relación con la identificación, reconocimiento, medición, valoración y revelación de "intangibles" en la información contable de las empresas en Popayán.

Un análisis descriptivo y econométrico. Cuadernos de Contabilidad, 16 (40), 111150. http://dx.doi.org/10.11144/Javeriana. cc16-40.gcai 